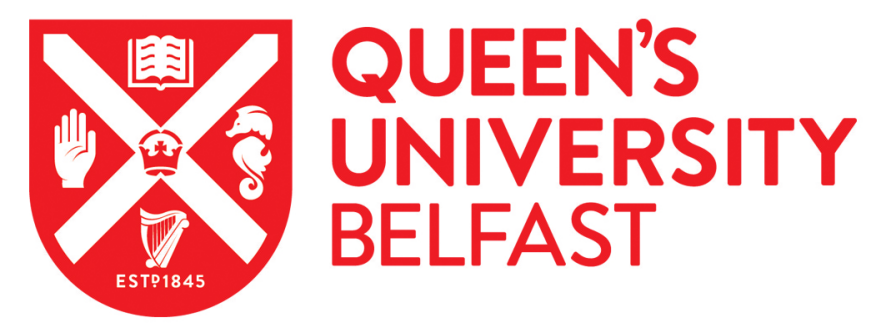

\title{
Effect of slag content and activator dosage on the resistance of fly ash geopolymer binders to sulfuric acid attack
}

Aiken, T., Kwasny, J., Sha, W., \& Soutsos, M. (2018). Effect of slag content and activator dosage on the resistance of fly ash geopolymer binders to sulfuric acid attack. Cement and Concrete Research, 111, 23-40. https://doi.org/10.1016/j.cemconres.2018.06.011

Published in:

Cement and Concrete Research

Document Version:

Peer reviewed version

Queen's University Belfast - Research Portal:

Link to publication record in Queen's University Belfast Research Portal

Publisher rights

Copyright 2018 Elsevier. This manuscript is distributed under a Creative Commons Attribution-NonCommercial-NoDerivs License

(https://creativecommons.org/licenses/by-nc-nd/4.0/), which permits distribution and reproduction for non-commercial purposes, provided the author and source are cited.

\section{General rights}

Copyright for the publications made accessible via the Queen's University Belfast Research Portal is retained by the author(s) and / or other copyright owners and it is a condition of accessing these publications that users recognise and abide by the legal requirements associated with these rights.

Take down policy

The Research Portal is Queen's institutional repository that provides access to Queen's research output. Every effort has been made to ensure that content in the Research Portal does not infringe any person's rights, or applicable UK laws. If you discover content in the Research Portal that you believe breaches copyright or violates any law, please contact openaccess@qub.ac.uk. 
Effect of slag content and activator dosage on the resistance of fly ash geopolymer binders to sulfuric acid attack

Authors: Timothy A Aiken ${ }^{1}$, Jacek Kwasny ${ }^{1}$, Wei Sha ${ }^{1}$, Marios N Soutsos ${ }^{1}$

${ }^{1}$ School of Natural and Built Environment, Queen's University Belfast, Stranmillis Road, Belfast, BT9 5AG, UK

\begin{abstract}
:
Geopolymer (GP) binders are an appealing alternative to Portland cement (PC) binders as they have the potential to reduce the $\mathrm{CO}_{2}$ emissions associated with the cement and concrete industry. However, their durability in aggressive environments needs thorough examination if they are to become a viable alternative to traditional Portland cement (PC) materials. This study investigated the effect of increasing slag content and activator dosage on the sulfuric acid resistance of fly ash GP binders. Their performance was also compared with that of neat PC mixes using various physical and microstructural techniques. The results show that increasing the slag content of fly ash GPs decreases porosity, but makes the reaction products more susceptible to sulfuric acid attack. It was also found that increasing the alkaline activator dosage of fly ash GPs has little impact on sulfuric acid resistance. Finally, GP binders displayed superior sulfuric acid resistance than their PC counterparts.
\end{abstract}

Keywords: Microstructure (B), Degradation (C), Durability (D), Alkali activated cement (D), Acid attack

\title{
1. Introduction
}

The durability of concrete is an increasingly important property for concrete structures due to the growing demand for structures to have a long service life with minimal maintenance [1]. It is well known that traditional Portland cement (PC) concrete structures deteriorate when exposed to acidic environments [2]. Such conditions reduce the service life and increase the cost for maintenance or renewal, which is also harmful for the environment in terms of $\mathrm{CO}_{2}$ emissions and natural resource conservation [3]. There are many ways in which concrete can come into contact with aggressive acidic media and there are numerous types of acid which are harmful to cementitious materials including mineral and organic acids. This study focuses on sulfuric acid which poses a considerable threat to the durability of concrete in multiple scenarios which are discussed below. Many industrial manufacturing processes such as fertiliser production and metal finishing use mineral acids such as sulfuric acid [4]. Acid precipitation is another common source of acid attack which occurs due to the incomplete combustion of fuels and industrial pollutants producing sulphur gases which form sulfuric acid when reacted with water [5], [6]. Additionally, sewer networks and wastewater systems suffer significant 
corrosion and deterioration due to sulfuric acid worldwide, resulting in large economic losses annually [7], [8]. Sulfuric acid, generated by sulphur/sulphide-oxidising bacteria has been identified as the corroding acid in sewer systems [9]-[11]. Unfortunately, the relative inaccessibility of sewer networks poses considerable challenges for maintenance and repair [12]. Sulfuric acid can also be present in groundwater or produced from the oxidation of sulphur bearing compounds in backfill, such as pyrite, causing degradation to concrete substructures [13]. The dissolution of hydrogen sulphide can also form sulfuric acid with a low $\mathrm{pH}$ on the concrete walls of geothermal wells [14]. Therefore, sulfuric acid is a major cause of degradation of concrete structures.

In order to reduce the $\mathrm{CO}_{2}$ emissions related to the production of $\mathrm{PC}$, the use of geopolymer (GP) materials has become an increasingly active area of research. GPs are alternative binding materials which are produced using materials such as ground granulated blast furnace slag (slag) and fly ash (also known as pulverised fuel ash). These materials are activated or hardened using solutions of alkali silicates and/or hydroxides [15]. Natural clays such as kaolinite in the form of metakaolin are also used to produce GP materials [16], [17] but are not the focus of the present study. Fly ash and slag are considered promising binder materials due to environmental benefits as they are by-products from other industries and can help reduce the demand for $\mathrm{PC}$, and in turn, reduce $\mathrm{CO}_{2}$ emissions. The production of 1 tonne of PC clinker emits $c a$. 0.9 tonnes of $\mathrm{CO}_{2}$. Approximately $8 \%$ of global $\mathrm{CO}_{2}$ emissions are attributed to PC production [18]-[20]. However, geopolymer concrete produced with fly ash and slag has been shown to have between 50 and $90 \%$ less embodied $\mathrm{CO}_{2}$ than PC concrete [21][23]. It is worth noting that the environmental benefit will vary depending on the source materials, transportation requirements and activator type [24]. Fly ash is a by-product from coal combustion, however the demand for fly ash as a construction material is increasing. Nonetheless, there are still many countries where efficient utilisation of fly ash is a major problem with as little as $7 \%$ being used effectively [25]. Slag is a by-product of steel manufacture and is produced when blast furnace slag is cooled rapidly in water resulting in glassy granules, these are then ground to form a fine powder [26]. It is important to determine the resistance of GP materials to acid attack in comparison with traditional PC materials before their use can become widespread. Potentially, GPs may be able to solve two of the main problems for traditional PC materials, namely, the large volume of $\mathrm{CO}_{2}$ emissions and low resistance to aggressive acidic media.

The majority of studies in the literature on the acid resistance of GP materials report favourable performance. Rostami and Brendley [27] studied the sulfuric acid resistance of fly ash concrete and PC concrete with the addition of silica fume. After 90 days exposure to $20 \%$ sulfuric acid the fly ash concrete had a mass loss in the region of $4 \%$ compared with $25 \%$ for the PC based concrete. Similarly, Thokchom et al. [28] reported that fly ash GP mortars had much better performance in terms of mass loss when exposed to $10 \%$ sulfuric acid than their heavily corroded PC counterparts. An increase in 
mass loss was also reported when the alkali dosage $\left(\%\right.$ of $\left.\mathrm{Na}_{2} \mathrm{O}\right)$ was increased. However, in a later publication it was stated that increasing the alkali dosage results in a higher residual compressive strength after sulfuric acid attack [29]. Bakharev [30] studied the resistance of fly ash GP pastes and PC pastes to 5\% sulfuric acid. A superior performance was observed for the fly ash GP paste which was attributed to much lower calcium content. Lee and Lee [31] studied the resistance of fly ash and slag GP mortars to $10 \%$ sulfuric acid. They reported higher resistance of blends with lower slag content due to the nature of the binding gel produced. On the other hand, Lloyd et al. [32] reported that increasing the slag content increases the resistance of GP pastes exposed to sulfuric acid with $\mathrm{pH}$ controlled at 1.0. Allahverdi and Skvara [33], [34] studied the mechanism of sulfuric acid attack on fly ash and slag GP pastes containing $50 \%$ of each. They reported an ion exchange between the samples and attacking acid followed by shrinkage cracks and the formation of gypsum.

Many different variables have been studied including sample type, sample size, acid type and acid severity [35]. There are also many testing procedures and degradation indicators employed making it difficult to draw comparisons between studies [35]. Additionally, many studies only consider a single deterioration mechanism and few studies consider multiple indicators of deterioration which is necessary when studying different binder types. Acid attack is a complex phenomenon, particularly when studying different binder types. Therefore many indicators of acid attack were employed in this investigation including, physical, leaching and microstructural properties. Even when studying the acid attack of PC materials alone the use of multiple test methods is recommended to ensure a reliable estimation of acid resistance is achieved [36]. Furthermore, despite resistance to aggressive environments often being cited as a benefit of GP materials, there remain limitations in the understanding of the effects of acid attack to GP materials, particularly at microstructural level [37]. Therefore, the overall aim of this work was to study the sulfuric acid resistance of fly ash based GP mortars and pastes and to understand the mechanism of sulfuric acid attack. The main objectives were to:

- Investigate influence of slag content on the sulfuric acid resistance of fly ash GP mixes,

- Determine the effect of increased activator dosage on the sulfuric acid resistance of neat i.e unblended fly ash GP mixes,

- Compare the sulfuric acid resistance of GP mixes with conventional PC mixes.

\section{Experimental programme}

\subsection{Methodology}

In order to satisfy the objectives, the following variables were investigated: 
- The effect of the slag content on the acid resistance of fly ash GPs has been assessed by increasing the slag content in both mortar and paste mixes, i.e. $0 \%, 20 \%, 40 \%$ and $70 \%$ for mixes GP1, GP2, GP3 and GP4, respectively. All four mixes had $\mathrm{Na}_{2} \mathrm{O}$ content of $7.5 \%$ and $\mathrm{Na}_{2} \mathrm{O} / \mathrm{SiO}_{2}$ ratio of 1.25 .

- The effect of increasing the alkaline activator dosage on the acid resistance of $100 \%$ fly ash GPs has been studied on mortar and paste mixes with different $\mathrm{Na}_{2} \mathrm{O}$ content and $\mathrm{Na}_{2} \mathrm{O} / \mathrm{SiO}_{2}$ ratio, i.e. $7.5 \%$ and 1.25 for mix GP1 and $11.5 \%$ and 0.95 for mix GP5.

- PC mortar and paste mixes with two different strength grades were used to allow comparison of GP and PC mortars with similar compressive strength. Mix PC1 had a comparable compressive strength to that of GP2 and GP5, while mix PC2 had a comparable compressive strength to that of GP3 and GP4.

All the mortar mixes investigated in this study were prepared with a paste content of $50 \%$, so a fair comparison could be carried out between different binder types.

After 28 days of curing, mortar samples were immersed in 1, 3 and 5\% sulfuric acid (w/w) solutions for a total duration of 56 days, while paste samples were immersed in 5\% sulfuric acid solutions for 21 days. For both mortars and pastes the acid solutions were replenished every 7 days. Mortar mixes were used to study physical properties such as visual appearance, mass change, compressive strength, alkalinity loss and porosity. Paste mixes were used to study the leaching behaviour by $\mathrm{pH}$ and inductively coupled plasma mass spectrometry (ICP) analysis of the acid solutions. The paste mixes were also used to study microstructural properties by X-ray diffraction (XRD), thermogravimetric analysis (TGA), Fourier transform infrared spectroscopy (FTIR), scanning electron microscopy (SEM) and energy dispersive X-ray (EDX) analysis. Paste mixes exposed to acid attack were compared with control paste mixes stored in water. For convenience, the overall outline of the testing programme is shown in Table 1, while a detailed description of each testing method is provided in section 2.5 on testing procedures. 
Table 1 Outline of testing programme.

\begin{tabular}{|c|c|c|c|}
\hline \multirow{2}{*}{$\begin{array}{l}\text { Type of tested } \\
\text { property }\end{array}$} & \multirow{2}{*}{$\begin{array}{l}\text { Tested } \\
\text { property }\end{array}$} & \multicolumn{2}{|c|}{ Testing details } \\
\hline & & Mortar mixes & Paste mixes \\
\hline \multirow{5}{*}{$\begin{array}{l}\text { Physical } \\
\text { properties }\end{array}$} & $\begin{array}{c}\text { Visual } \\
\text { appearance }\end{array}$ & $\begin{array}{l}\text { Tested every } 7 \text { days (before } \\
\text { acid solution replacement) } \\
\text { during the } 56 \text { days of } \\
\text { samples exposure to acid } \\
\text { solution. }\end{array}$ & 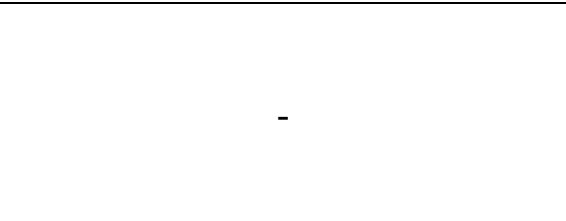 \\
\hline & Mass change & As above. & - \\
\hline & $\begin{array}{l}\text { Compressive } \\
\text { strength }\end{array}$ & $\begin{array}{l}\text { Tested at the end of the } 56 \\
\text { days of samples exposure to } \\
\text { acid solution. Control } \\
\text { samples stored in water were } \\
\text { tested at the same age. }\end{array}$ & - \\
\hline & Alkalinity loss & $\begin{array}{l}\text { Tested at the end of the } 56 \\
\text { days of samples exposure to } \\
\text { acid solution. }\end{array}$ & - \\
\hline & Porosity & $\begin{array}{l}\text { Control samples were tested } \\
\text { at the age of } 28 \text { days. }\end{array}$ & - \\
\hline \multirow[b]{2}{*}{$\begin{array}{l}\text { Leaching } \\
\text { behaviour }\end{array}$} & $\mathrm{pH}$ & 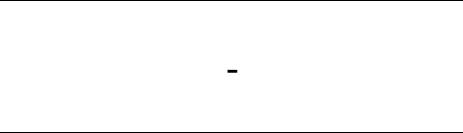 & $\begin{array}{l}\text { Acid solution was tested at suitable } \\
\text { intervals between every } 7 \text { day acid } \\
\text { solution replacement. }\end{array}$ \\
\hline & ICP analysis & - & $\begin{array}{l}\text { Acid solution was tested every } 7 \\
\text { days (before acid solution } \\
\text { replacements) during the } 21 \text { days of } \\
\text { acid test. For comparison, water } \\
\text { used for storing the control samples } \\
\text { was tested at the same intervals. }\end{array}$ \\
\hline \multirow{4}{*}{$\begin{array}{l}\text { Microstructural } \\
\text { properties }\end{array}$} & XRD & - & $\begin{array}{l}\text { Tested on powdered samples at the } \\
\text { end of } 21 \text { days of acid attack. For } \\
\text { comparison, control samples stored } \\
\text { in water were tested. }\end{array}$ \\
\hline & TGA & - & As above. \\
\hline & FTIR & - & As above. \\
\hline & SEM/EDX & - & $\begin{array}{l}\text { Tested on sectioned and polished } \\
\text { samples at the end of } 21 \text { days of } \\
\text { acid attack and control samples. }\end{array}$ \\
\hline
\end{tabular}

\subsection{Materials}

The fly ash used in this study was obtained from Power Minerals Ltd., Drax Power Station, North Yorkshire, UK and the slag was supplied by Civil and Marine Ltd-Hanson Company, member of the Heidelberg Cement Group, Essex, UK. The fly ash and slag conform to the standards of BS EN 4501:2012 [38] and BS EN 15167-1:2006, respectively [39]. Portland cement CEM I 42.5N, produced by Quinn Cement in Northern Ireland, and conforming to the standards of BS EN197-1:2011 [40] was used as PC. The oxide compositions for fly ash, slag and PC obtained by X-ray florescence (XRF) are displayed in Table 2. The XRD patterns of fly ash, slag and PC are shown in Fig. 1. The main crystalline phases present in fly ash are quartz, mullite and hematite. The slag is almost completely amorphous with a broad peak or hump shown between 25 and $35^{\circ} 2 \theta$. The PC has many crystalline phases including alite, belite, aluminate, brownmillerite and gypsum. 
The alkali activated fly ash and slag binders were activated by solutions of sodium silicate and sodium hydroxide. The sodium silicate solution was supplied by Fisher Scientific and consisted of 12.8\% $\mathrm{Na}_{2} \mathrm{O}, 25.5 \% \mathrm{SiO}_{2}$ and $61.7 \%$ water. The sodium hydroxide solution was prepared at $30 \% \mathrm{w} / \mathrm{w}$ by the dissolution of solid commercial grade ( $99 \%$ purity) sodium hydroxide and was allowed to cool to room temperature prior to sample preparation.

The aggregate used was siliceous lough sand abundant in quartz, sourced locally in Northern Ireland. Silica sand is not susceptible to acid attack allowing comparison to be carried out between the different pastes without dissolution of aggregate [41]. The sand had an oven-dry particle density of $2695 \mathrm{~kg} / \mathrm{m}^{3}$ and water absorption of 0.92 and $1 \%$ after 1 and 24 hours, respectively. Both density and water absorption were determined according to BS 812-2:1995 [42]. The sand was oven dried at $105 \pm$ $5{ }^{\circ} \mathrm{C}$ for at least $48 \mathrm{~h}$ to remove all moisture. It was then allowed to cool and stored in dry conditions before mixing.

Laboratory reagent grade sulfuric acid $\left(95-97 \% \mathrm{H}_{2} \mathrm{SO}_{4}\right)$ was used to prepare the acid solutions by mixing with distilled water at 1,3 and $5 \%(\mathrm{w} / \mathrm{w})$.

Table 2 Oxide compositions and loss on ignition (LOI) of fly ash, slag and PC.

\begin{tabular}{lrrrrrrrrrrr}
\hline Material & $\mathrm{CaO}$ & $\mathrm{SiO}_{2}$ & $\mathrm{Al}_{2} \mathrm{O}_{3}$ & $\mathrm{Fe}_{2} \mathrm{O}_{3}$ & $\mathrm{Na}_{2} \mathrm{O}$ & $\mathrm{K}_{2} \mathrm{O}$ & $\mathrm{SO}_{3}$ & $\mathrm{MgO}$ & $\mathrm{TiO}_{2}$ & $\mathrm{MnO}$ & LOI \\
\hline Fly ash & 2.24 & 46.78 & 22.52 & 9.15 & 0.89 & 4.09 & 0.90 & 1.33 & 1.05 & 0.05 & 3.57 \\
Slag & 43.72 & 29.38 & 11.23 & 0.36 & 1.05 & 0.93 & 1.76 & 6.94 & 0.67 & 0.51 & 2.40 \\
PC & 63.01 & 20.21 & 4.79 & 2.78 & 0.19 & 0.59 & 2.60 & 1.93 & 0.27 & 0.08 & 3.16 \\
\hline
\end{tabular}




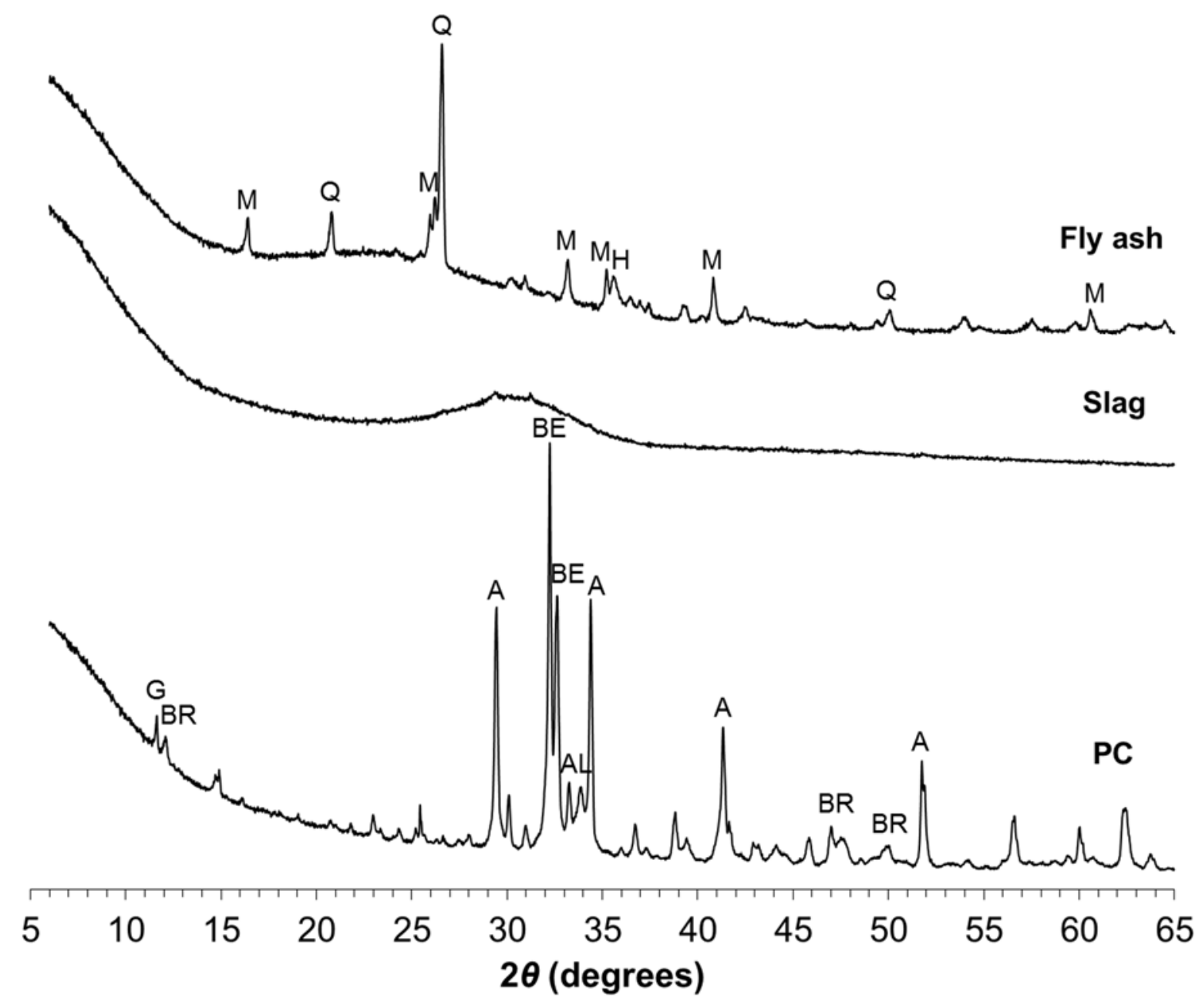

Fig. 1. XRD patterns of fly ash, slag and PC (M - mullite, Q - quartz, H - hematite, G - gypsum, BR brownmillerite, A - alite, $\mathrm{BE}$ - belite, $\mathrm{AL}$ - aluminate).

\subsection{Mix proportions}

The mortar mix proportions used are presented in Table 3. The GP mixes are based on mix design optimisation carried out by Rafeet et al. [43]-[45] and Vinai et al. [19] and the PC mix proportions were obtained from work carried out by Kwasny et al. [46]-[48]. The paste content was kept constant at $50 \%$ for all mortars, so that a fair comparison could be carried out between different mixes. The water/solid ratio is calculated from the ratio of water to binder content including the solid and water proportions of the activating solutions. Additional water described as absorption water was added to bring the sand to saturated surface dry condition following oven drying. The alkali dosage $(\mathrm{M}+)$ is defined as the percentage of $\mathrm{Na}_{2} \mathrm{O}$ in the binder. The mix proportions of the paste samples were identical to the mortars except they contained no sand. 
Table 3 Mix proportions for GP and PC mortars.

\begin{tabular}{|c|c|c|c|c|c|c|c|c|}
\hline \multicolumn{2}{|c|}{ Mix composition } & GP1 & GP2 & GP3 & GP4 & GP5 & PC1 & $\mathrm{PC} 2$ \\
\hline \multirow{3}{*}{$\begin{array}{c}\text { Binder } \\
\text { composition }\end{array}$} & Fly ash (\%) & 100 & 80 & 60 & 30 & 100 & - & - \\
\hline & Slag $(\%)$ & 0 & 20 & 40 & 70 & 0 & - & - \\
\hline & $\mathrm{PC}(\%)$ & - & - & - & - & - & 100 & 100 \\
\hline \multicolumn{2}{|c|}{ Paste content $(\%)$} & 50 & 50 & 50 & 50 & 50 & 50 & 50 \\
\hline \multicolumn{2}{|c|}{ Water/solid ratio } & 0.37 & 0.38 & 0.40 & 0.42 & 0.37 & - & - \\
\hline \multicolumn{2}{|c|}{ Water/cement ratio } & - & - & - & - & - & 0.60 & 0.42 \\
\hline \multicolumn{2}{|c|}{ Alkali dosage (M+) } & 7.5 & 7.5 & 7.5 & 7.5 & 11.5 & - & - \\
\hline \multicolumn{2}{|c|}{$\mathrm{Na}_{2} \mathrm{O} / \mathrm{SiO}_{2}$} & 1.25 & 1.25 & 1.25 & 1.25 & 0.95 & - & - \\
\hline \multicolumn{2}{|c|}{ Fly ash $\left(\mathrm{kg} / \mathrm{m}^{3}\right)$} & 577 & 463 & 344 & 172 & 538 & - & - \\
\hline \multicolumn{2}{|c|}{ Slag $\left(\mathrm{kg} / \mathrm{m}^{3}\right)$} & - & 116 & 229 & 401 & - & - & - \\
\hline \multicolumn{2}{|c|}{ Portland cement $\left(\mathrm{kg} / \mathrm{m}^{3}\right)$} & - & - & - & - & - & 544 & 676 \\
\hline \multicolumn{2}{|c|}{ Sodium silicate $\left(\mathrm{kg} / \mathrm{m}^{3}\right)$} & 136 & 136 & 135 & 135 & 256 & - & - \\
\hline \multicolumn{2}{|c|}{ Sodium hydroxide $\left(\mathrm{kg} / \mathrm{m}^{3}\right)$} & 111 & 112 & 111 & 111 & 126 & - & - \\
\hline \multicolumn{2}{|c|}{ Sand $\left(\mathrm{kg} / \mathrm{m}^{3}\right)$} & 1348 & 1348 & 1348 & 1348 & 1348 & 1348 & 1348 \\
\hline \multicolumn{2}{|c|}{ Absorption water $\left(\mathrm{kg} / \mathrm{m}^{3}\right)$} & 12 & 12 & 12 & 12 & 12 & 12 & 12 \\
\hline \multicolumn{2}{|c|}{ Total added water $\left(\mathrm{kg} / \mathrm{m}^{3}\right)$} & 93 & 100 & 112 & 125 & 13 & 339 & 296 \\
\hline
\end{tabular}

\subsection{Procedure for mix preparation, samples manufacturing and curing}

Mortar and paste samples were prepared using a $10 \mathrm{~L}$ capacity planar-action high-shear mixer. To begin with, the oven dried sand was placed in the mixing bowl with half of the total added water for 15 mins to allow the sand to absorb moisture (this step was not necessary for paste samples as they contained no sand). The appropriate dry binder component of each mix was then added to the mixing bowl and mixed together with the sand. The water and/or activating solutions were then added and mixing continued for 6 mins before casting.

The samples were cast in two layers into $50 \mathrm{~mm}$ three-gang plastic moulds and compacted using a vibrating plate. Afterwards, they were placed into the appropriate curing conditions, depending on sample type. The GP mixes containing 100\% fly ash (GP1 and GP5) were cured at $70{ }^{\circ} \mathrm{C}$ for 7 days and then placed at $20 \pm 1{ }^{\circ} \mathrm{C}$ and $50 \%$ humidity. The fly ash and slag mixes (GP2, GP3 and GP4) and the PC mixes (PC1 and PC2) were cured at $20 \pm 1{ }^{\circ} \mathrm{C}$ and relative humidity of greater than $90 \%$. Samples were demoulded 24 hours after casting and immediately returned to the appropriate curing conditions until they were further processed or tested.

\subsection{Testing procedures}

Acid resistance was tested based on the general guidelines provided in ASTM C267 [49]. Following 28 days of curing four mortar specimens from each mix were submerged in 1, 3 and 5\% solutions of sulfuric acid with an acid solution to sample volume ratio of 0.9 . The mortar samples were exposed to acid attack for a total of 56 days. Every 7 days visual inspection was carried out, the mass of the mortars was recorded and the acid solution was replenished. After 56 days of acid attack the 
compressive strength was determined for comparison with the compressive strength of control samples which were tested at the same age as the samples exposed to acid. The average compressive strength was determined by testing three specimens (a constant load rate of $50 \mathrm{kN} / \mathrm{min}$ was applied). To minimise the effect of the corroded surface protective soft board was used on the loading surfaces of each sample. The compressive strength was calculated using the samples original cross-sectional area before any erosion took place as previously done by Bassuoni et al. [13]. The remaining fourth specimen was used to determine the alkalinity loss. This was achieved by splitting the cubes and applying phenolphthalein solution on the split surface which highlights the region (deep pink/purple) where the $\mathrm{pH}$ is greater than approximately 9 [50]-[53]. The width of this region on each sample was measured in two directions and subtracted from the original width of each sample $(50 \mathrm{~mm})$. This value was then expressed as a percentage of the original width. This percentage includes the depth of each sample which has been removed due to deterioration and the depth where the $\mathrm{pH}$ was less than 9.0, hence, alkalinity loss (\%). The alkalinity loss values give some indication of how far the acid has penetrated into each sample or at least to what extent significant ion exchange has taken place between the sample and acid solution. The pore structure of the mortar mixes was also assessed to obtain their porosity (\%) by mercury intrusion porosimetry (MIP) according to BS ISO 15901-1:2005 [54].

After 28 days of curing the paste mixes were submerged in 5\% sulfuric acid solution for 21 days. Similar to the mortars the acid solution was replenished every 7 days and the $\mathrm{pH}$ was recorded at suitable intervals during each cycle of acid attack. Inductively coupled plasma mass spectrometry (ICP) was used to analysis the acid solution every 7 days to determine what elements had leached from the paste samples into the acid solution. The paste samples were used for microstructural analysis in an attempt to identify and compare the mechanism of attack for each binder type. They were compared with control paste samples which were submerged in water instead of acid. Powdered samples were obtained by crushing and grinding in a pestle and mortar the outside layer of both control samples and samples exposed to acid. The powders were dried in a desiccator at $35{ }^{\circ} \mathrm{C}$ for 24 hours prior to analysis. The following analytical techniques were used:

- X-ray diffraction (XRD) with PANalytical X'Pert PRO diffractometer applying CuKa radiation of wavelength $1.54 \AA$. Diffraction patterns were collected between 5 and $65^{\circ} 2 \theta$ with a step size of $0.017^{\circ}$. PANalytical X'Pert Highscore software with the powder diffraction file (PDF) database was used to analyse the diffraction patterns.

- Thermogravimetric analysis (TGA) using Netzsch's TG 209. The temperature was increased from 20 up to $1000{ }^{\circ} \mathrm{C}$ at a rate of $10{ }^{\circ} \mathrm{C} / \mathrm{min}$ in a nitrogen environment. The weight loss information obtained from the TG curve and first derivative (DTG) was used to confirm the type of hydrates and reaction products. 
- Fourier transform infrared spectroscopy (FTIR) using Jasco 4100 series FTIR Spectrometer with attenuated total reflectance attachment. The spectra were gathered between 650 and 4000 $\mathrm{cm}^{-1}$ wavenumber at $8 \mathrm{~cm}^{-1}$ resolution.

- Scanning electron microscopy (SEM) with energy dispersive X-ray (EDX) analysis. The equipment used was QUANTA FEG250 with OXFORD X-Act as chemical composition analyser. EDX was run by Aztec version 2.0 software for chemical composition analysis. Paste samples were sectioned and polished in preparation for SEM and EDX analysis.

\section{Results}

This section reports the results obtained, detailed discussion is provided in section 4 where all of the results obtained are discussed together.

\subsection{Porosity}

Fig. 2 displays the porosity values at 28 days for the GP and PC mortars, one sample was examined for each mix. GP1 was found to have the largest porosity of 19\% followed by GP5 with a porosity of $17 \%$. These samples consisted of $100 \%$ fly ash and the higher alkaline activator dosage used in GP5 resulted in a reduced porosity. As the slag content increased, the porosity was found to decrease to 16 , 12 and 5\% for GP2, GP3 and GP4, respectively. This is similar to the trend reported by Lee and Lee [31] for mortars and Provis et al. [55] for pastes. The porosity of PC1 was $12 \%$ and PC2 was 10\%. Therefore, GP4 displayed the lowest porosity followed by PC2. Both PC1 and GP3 had porosities of $12 \%$ followed by GP2 which had a porosity of $16 \%$. Finally, the highest porosity values were obtained for the $100 \%$ fly ash samples. This is likely related to the binding gel formed in each system, sodium aluminium silicate hydrate (N-A-S-H) gel which is formed in fly as mixes is less dense and more porous than the space filling calcium aluminium silicate hydrate (C-A-S-H) or calcium sodium aluminium silicate hydrate (C-N-A-S-H) gel formed in slag dominant systems [56] or the calcium silicate hydrate (C-S-H) gel formed in PC binders [57], [58]. 


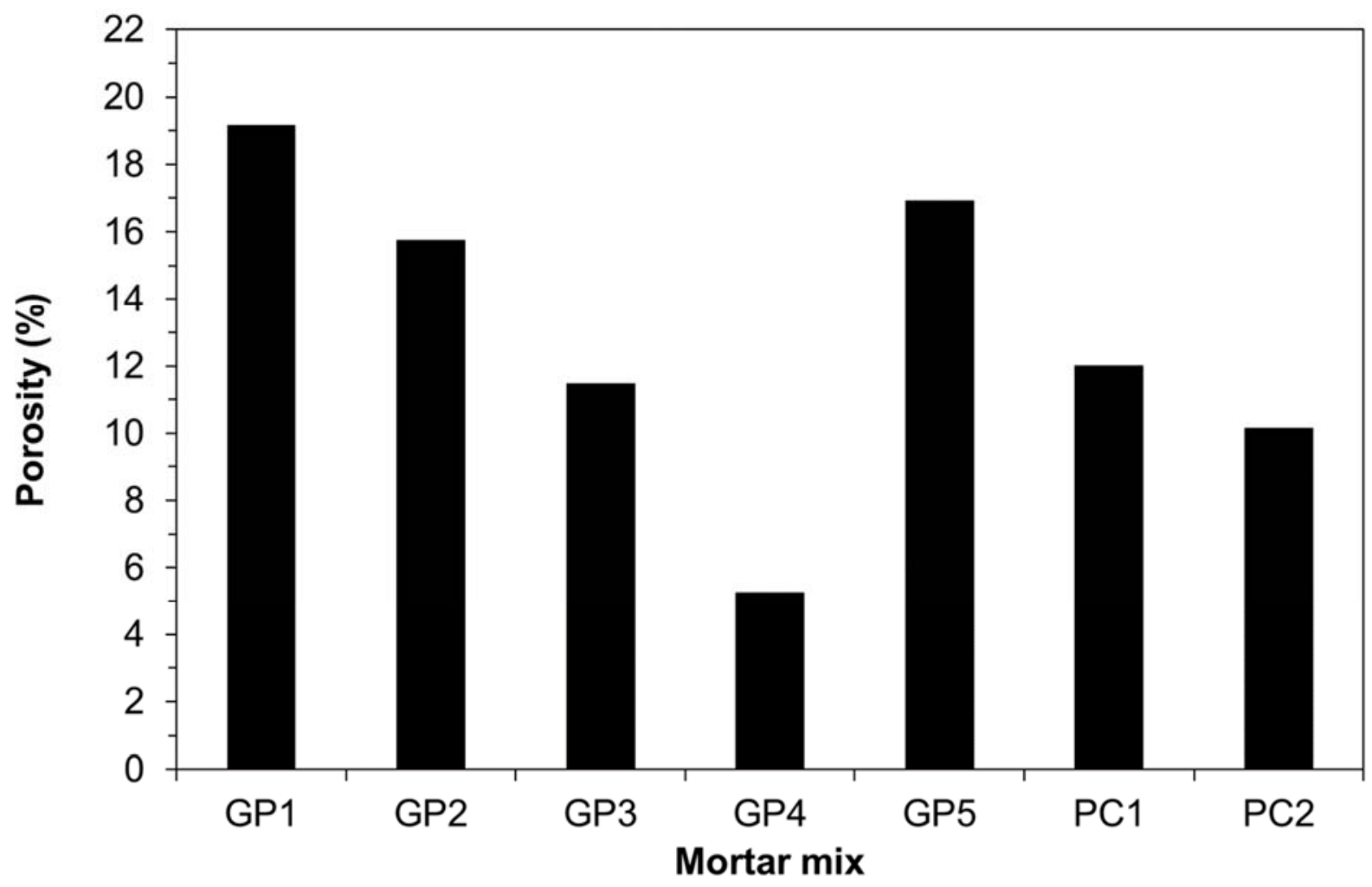

Fig. 2. Porosity of GP and PC mortars.

\subsection{Visual appearance}

Fig. 3 displays the appearance of the GP and PC mortars after exposure to 1, 3 and 5\% solutions of sulfuric acid. The same mixes unexposed to acid are also shown for comparison. As the acid concentration increased the visible damage observed also increased. The GP mortars have suffered limited visible damage in general, with almost no deterioration visible for the $100 \%$ fly ash samples (GP1 and GP5). The GP mortars which consist of both fly ash and slag show some GP paste loss and the exposure of sand particles which increases as the slag content increases (GP1 $<\mathrm{GP} 2<\mathrm{GP} 3<\mathrm{GP} 4$ ). Following exposure to 5\% sulfuric acid GP4 has cracks around the edge of the sample which may be related to expansion caused by the formation of additional products during the acid attack. The PC mortars have suffered the most visible damage, i.e. sand particles have been exposed due to the loss of cement paste from the surface and the edges of the samples appear rounded. 


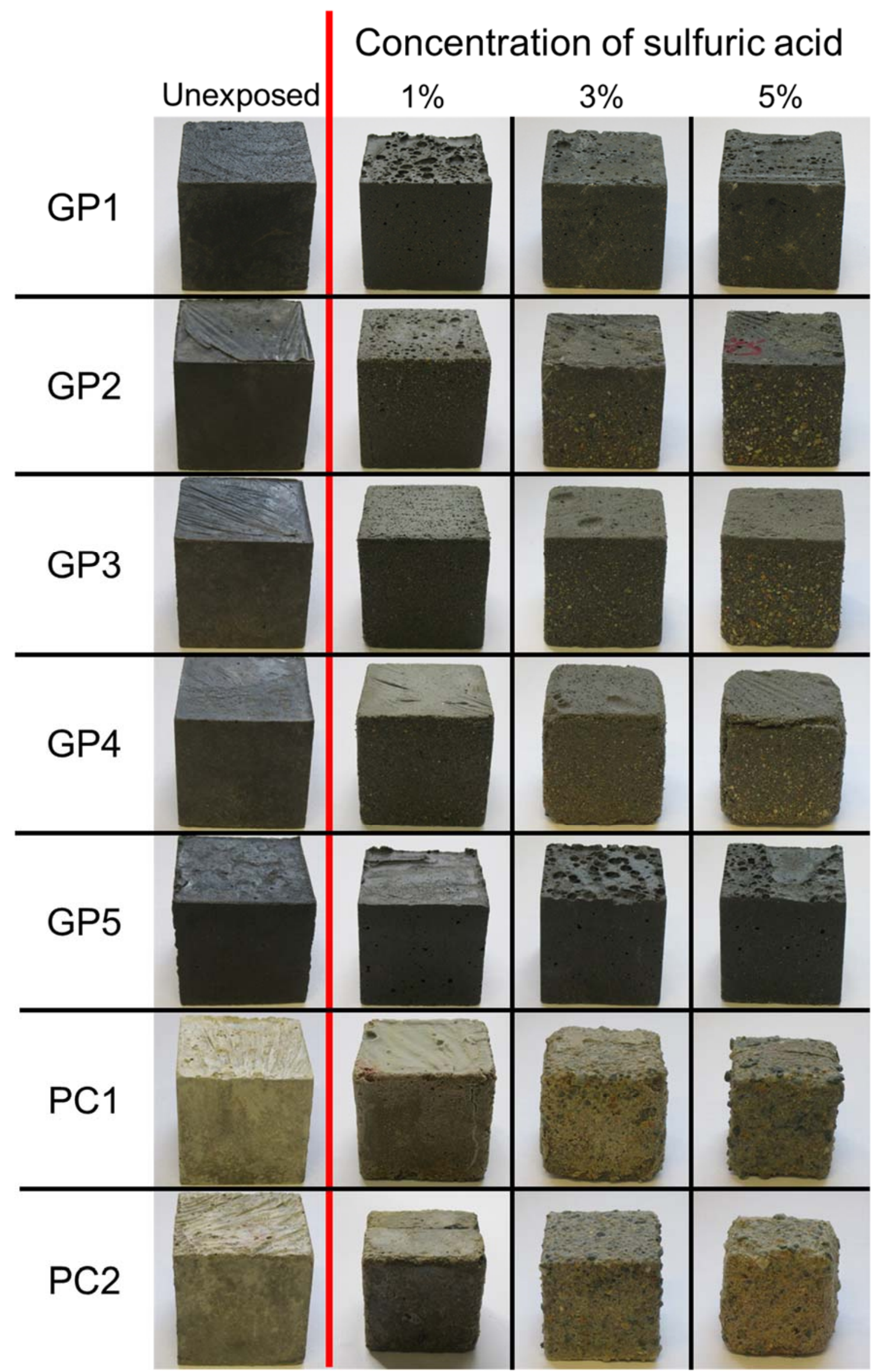

Fig. 3. Photographs of GP and PC mortars after 56 days exposure to 1,3 and $5 \%$ solutions of sulfuric acid. Unexposed samples are also shown. 


\subsection{Mass change}

Fig. 4 displays the mass change of each mortar mix during 56 days exposure to 1, 3 and 5\% solutions of sulfuric acid. The positive values represent a mass loss and the negative values represent a mass gain. Each data point shown in Fig. 4 is the average of measurements from four samples. The coefficient of variation (COV) was below 10 for $55 \%$ of values and below 20 for $75 \%$ of values. This was due to the non-uniform deterioration observed due to the formation of additional compounds during acid attack. It can be observed from Fig. 4 that the mass losses are more pronounced as the acid concentration increases, particularly in the case of the PC mixes. After exposure to $1 \%$ sulfuric acid (Fig. 4a) for 56 days, the GP mixes have mass losses below 1.4\%, except for GP2 which has a mass loss of $2.3 \%$. A small mass gain was reported for the PC mixes likely due to the formation of additional compounds during sulfuric acid exposure. After exposure to $3 \%$ sulfuric acid (Fig. 4b) for 56 days, GP1, GP3 and GP5 displayed mass losses between 2.1 and 2.8\%. GP2 had a mass loss of $5.5 \%$ whereas the mass of GP4 had very little change throughout. PC1 and PC2 had an increase in mass initially, but eventually after 56 days lost 4.5 and $16.3 \%$, respectively. Following exposure to 5\% sulfuric acid (Fig. 4c) GP2 had a mass loss of 7.6\% while GP1, GP3 and GP5 all lost approximately $3.4 \%$ of their initial mass after 56 days. Similar to $3 \%$ sulfuric acid exposure, very little mass change for GP4 was recorded throughout. The 5\% sulfuric acid was very destructive to the PC mixes. Mass losses of 28.3 and $34.6 \%$ were reported for PC1 and PC2, respectively, after 56 days. It is worth noting that some of the mass change values obtained after attack by sulfuric acid may be affected by the formation of additional compounds causing a reduction in the total mass loss or a mass increase. 

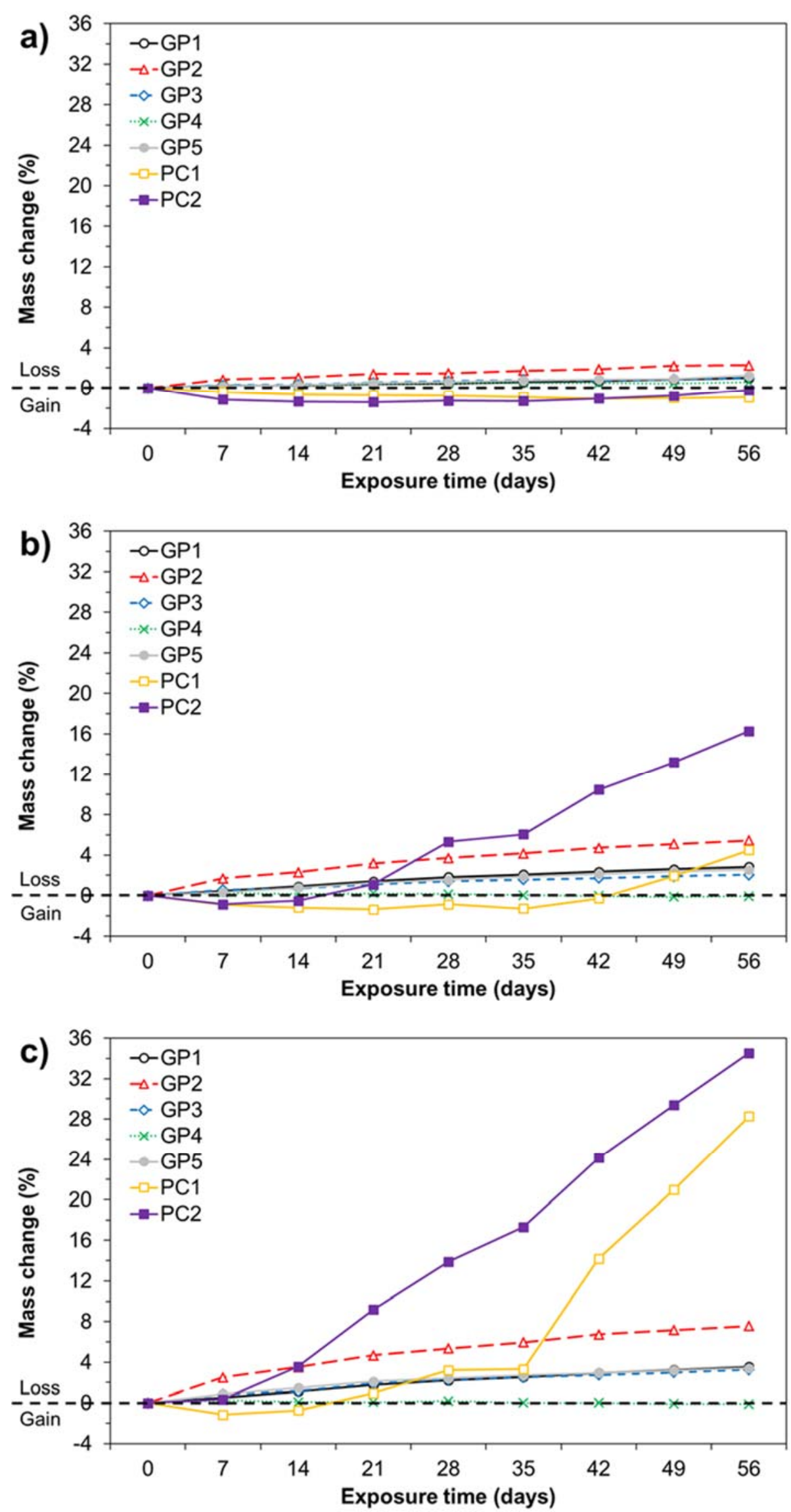

Fig. 4. Mass changes of GP and PC mortars during 56 days exposure to: a) $1 \%$ sulfuric acid, b) $3 \%$ sulfuric acid and c) $5 \%$ sulfuric acid. 


\subsection{Compressive strength}

Fig. 5 displays the compressive strength of the GP and PC mortars after exposure to 1, 3 and 5\% solutions of sulfuric acid for 56 days. The compressive of the same mixes unexposed to acid are also shown. The unexposed samples (stored in water) were tested at the same age ( 84 days) as the samples which were exposed to acid. The compressive strength of the GP mortars unexposed to acid increased as the percentage of slag in the binder increases (GP1 to GP4). Compressive strength values between 20 and $94 \mathrm{MPa}$ were observed. The 100\% fly ash sample with an increased activator dosage (GP5) displayed an increased compressive strength from $20 \mathrm{MPa}$ (GP1) to $55 \mathrm{MPa}$ (GP5). The PC mortars unexposed to acid had compressive strength values of 58 and $82 \mathrm{MPa}$. PC2 had a higher compressive strength due to the lower water cement ratio as displayed in Table 3.

As expected, each sample suffered a loss of strength due to acid exposure and the strength loss increased as the acid concentration increased. Furthermore, higher residual compressive strength was usually maintained for the mixes with larger initial compressive strength. Fig. 6 displays the percentage compressive strength loss of each mortar mix after exposure to acid. After exposure to $1 \%$ sulfuric acid the strength losses were between 23 and 52\%. After exposure to 3\% sulfuric acid the strength losses were all between 51 and $60 \%$. The strength losses after exposure to $5 \%$ solution were between 61 and $67 \%$ with the exception of PC1 which had a compressive strength loss of $74 \%$.

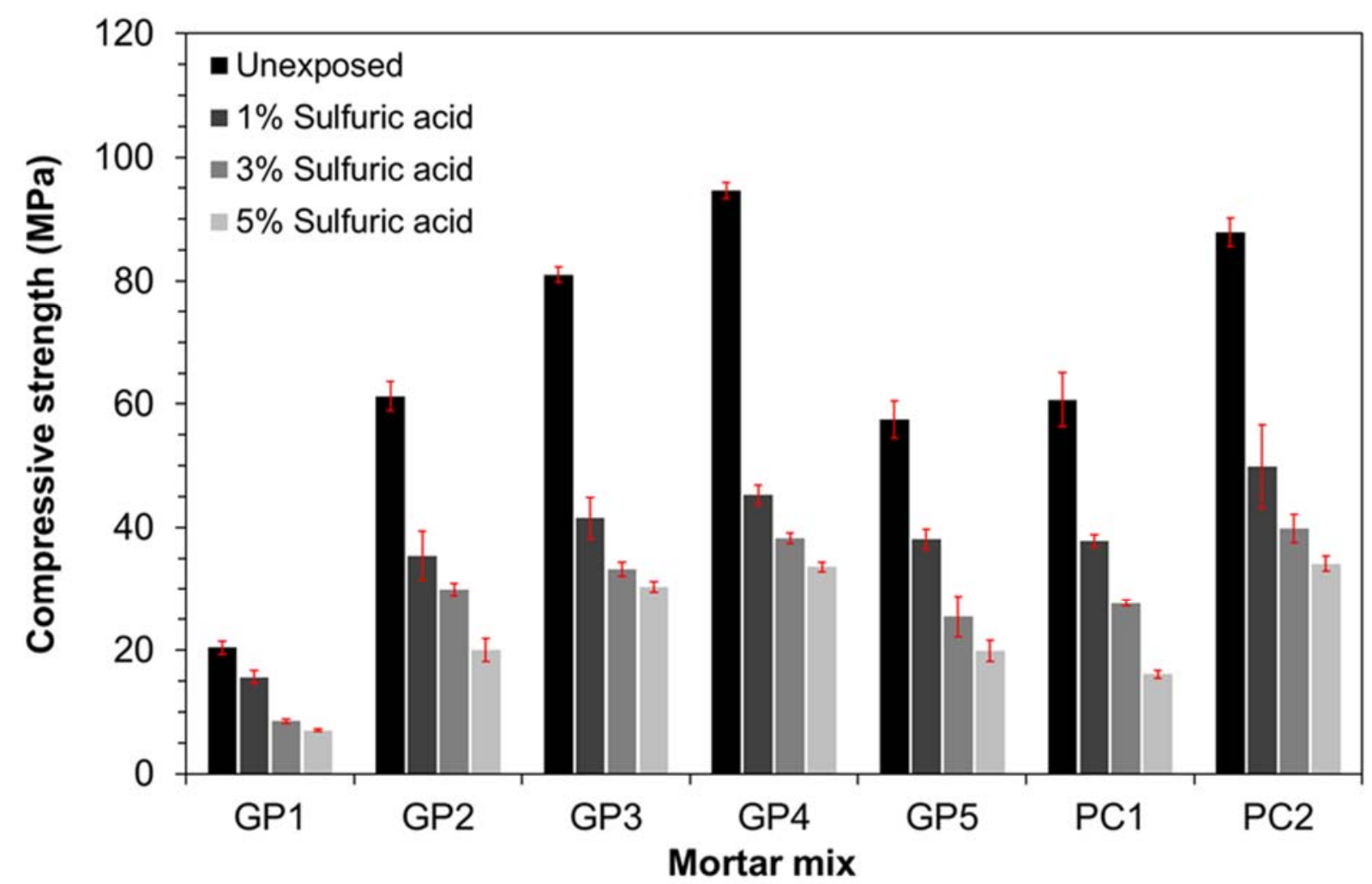

Fig. 5. Compressive strength of GP and PC mortars after exposure to 1, 3 and 5\% solutions of sulfuric acid for 56 days. Compressive strength of unexposed samples also shown. 


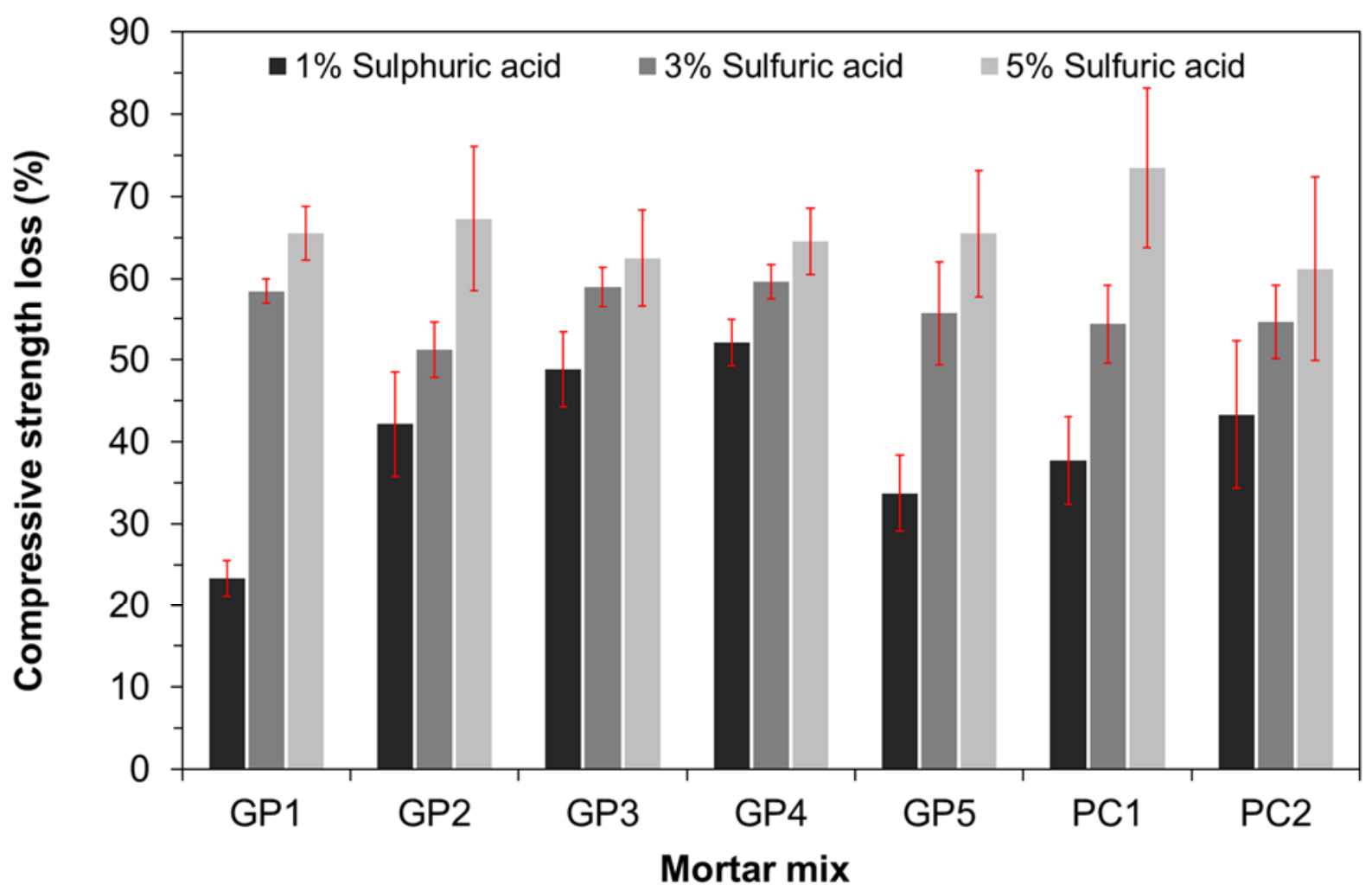

Fig. 6. Percentage compressive strength loss of GP and PC mortars after exposure to 1, 3 and 5\% solutions of sulfuric acid for 56 days.

\subsection{Alkalinity loss}

The alkalinity loss was determined by investigating the depth of the GP and PC mixes to which the $\mathrm{pH}$ has reduced below 9.0 including the depth of any material removed due to acid attack. This provides an indication of how far the acid has penetrated or how far into each mix significant ion exchange with the acid solution has taken place. Fig. 7 displays the photographs of the GP and PC mixes sprayed with phenolphthalein solution and Fig. 8 displays the alkalinity loss percentage of the GP and PC mixes after 56 days exposure to $5 \%$ sulfuric acid. The photographs of the unexposed samples are also shown and appear pink/purple throughout which shows that the initial $\mathrm{pH}$ of the entire cross section of each sample is above 9.0. It is worth noting that although this shows the $\mathrm{pH}$ is above 9.0 for each mix, the specific $\mathrm{pH}$ for each mix is not known. There may be some differences in the initial $\mathrm{pH}$ due to the different composition of each mix. Fig. 9 displays the evolution of the $\mathrm{pH}$ of water solutions during immersion in water of the equivalent paste mixes to the mortar mixes discussed here. Initially the $\mathrm{pH}$ of the water is 6.8 but increases over time during the samples immersion. Eventually the $\mathrm{pH}$ of the water solutions becomes stable which may provide an indication of the $\mathrm{pH}$ of the pore solution of each mix. There was only a small difference between each mix with values ranging between 11.5 and 12.5 following 21 days immersion. This suggests that the difference in the $\mathrm{pH}$ of the pore solution is small. Considering the low $\mathrm{pH}$ of $5 \%$ sulfuric acid (0.89), the effect of the small difference in $\mathrm{pH}$ of each samples pore solution should be almost negligible. 
The alkalinity loss was $100 \%$ for GP1 because the $\mathrm{pH}$ of the entire cross section dropped below 9.0. The alkalinity loss was recorded as 51, 32, 23 and 82\% for GP2, GP3, GP4 and GP5, respectively. Therefore, the alkalinity loss decreases as the slag content and alkaline activator dosage increases. The alkalinity loss was $19 \%$ for PC1 and 30\% for PC2. The PC samples exhibited similar performance to GP3 and GP4. However, the majority of the region which was considered to have lost alkalinity was removed due to the acid attack in the PC mixes. On the other hand, the majority of the region of the GP mixes which had lost alkalinity (i.e. been penetrated by acid) remained attached to the undamaged core. This suggests that GP mixes are able to withstand sulfuric acid penetration better than PC mixes. 


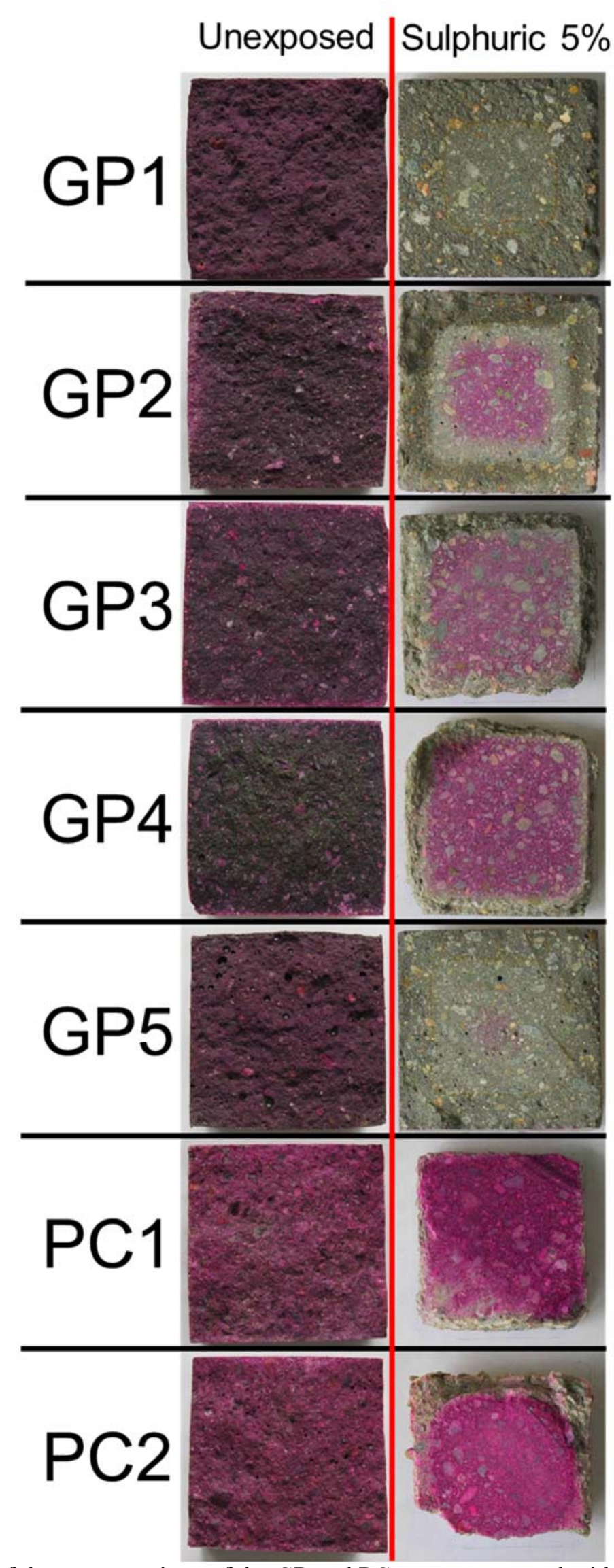

Fig. 7. Photographs of the cross sections of the GP and PC mortars sprayed with phenolphthalein solution including unexposed samples (stored in water) and samples after 56 days of exposure to 5\% sulfuric acid. 


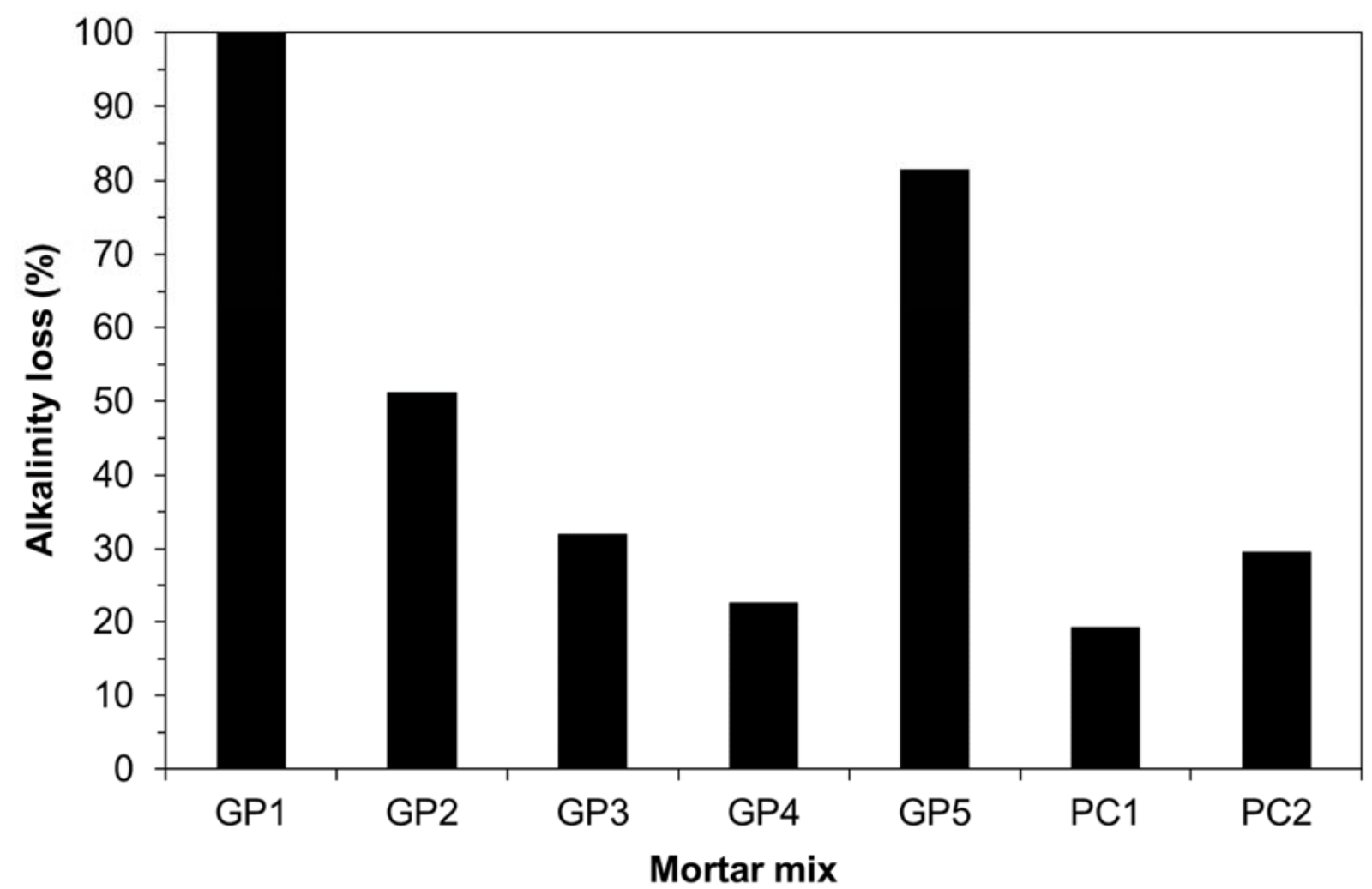

Fig. 8. Alkalinity loss of GP and PC mortars after 56 days exposure to $5 \%$ sulfuric acid.

\subsection{Leaching behaviour}

The leaching behaviour has been monitored by recording the $\mathrm{pH}$ of the $5 \%$ sulfuric acid solutions during immersion of pastes and performing elemental analysis on the leachate solution. Fig. 9 displays the evolution of the $\mathrm{pH}$ of the water solutions during 21 days of paste samples immersion. The water solution was replenished every 7 days to mimic the conditions for acid exposure. The initial $\mathrm{pH}$ of the water was 6.8 and it increased rapidly for all mixes to greater than 10.0 after 1 day of immersion and remained high until 7 days when the water was replenished. Similar behaviour was observed for each 7 day exposure period that followed. The increasing $\mathrm{pH}$ is due to the leaching of ions from the samples into the acid solution. This takes place because of the differential $\mathrm{pH}$ between the acid solution and samples which are alkaline in nature. These ion transfers were facilitated by the transfer of $\mathrm{H}^{+}, \mathrm{H}_{3} \mathrm{O}^{+}$ and $\mathrm{SO}_{4}{ }^{2-}$ from the sulfuric acid solution into the samples. The same procedure was performed with water as the leachate solution to compare the different leaching behaviour in water and sulfuric acid 


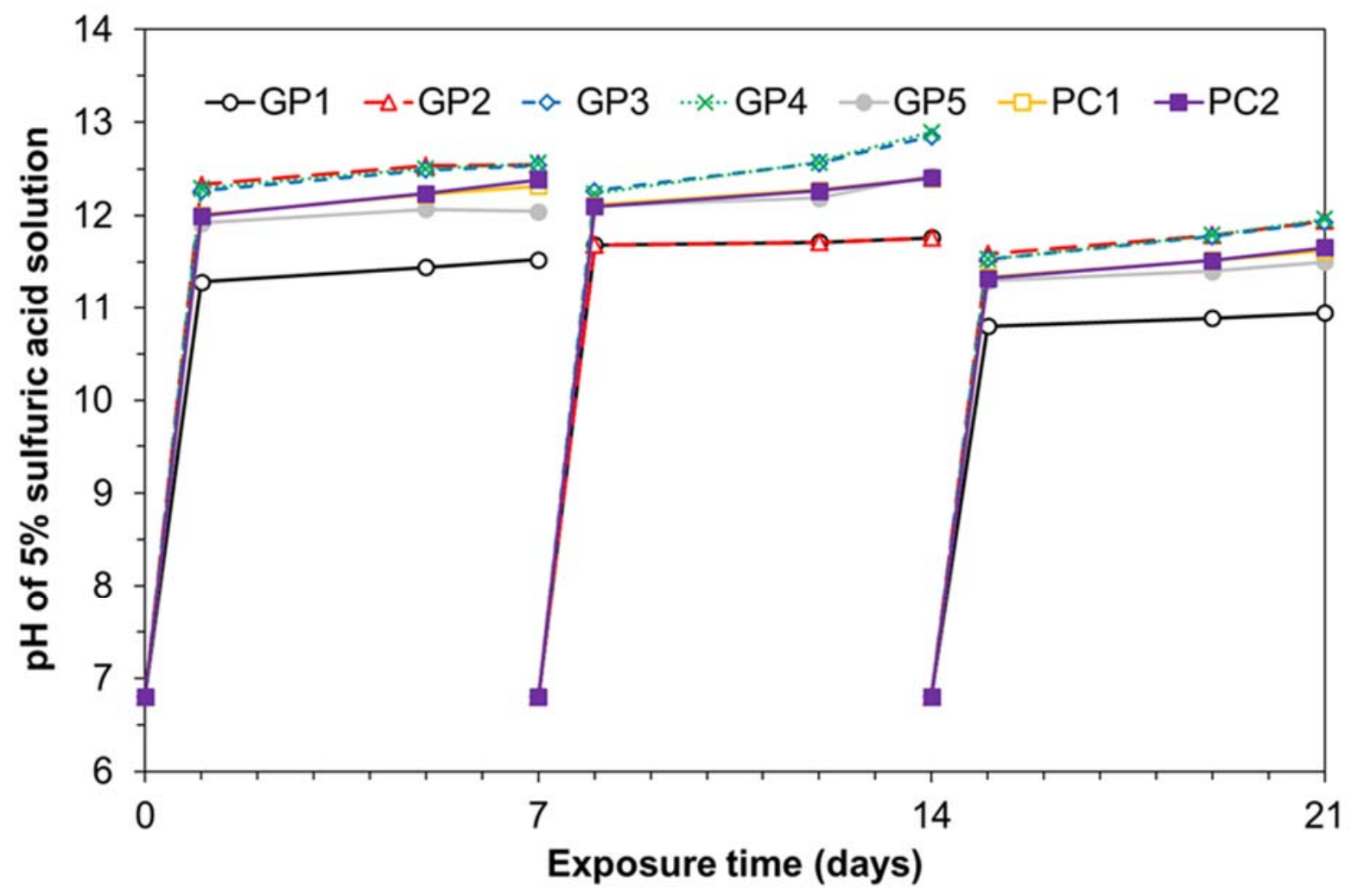

Fig. 9. $\mathrm{pH}$ of water solutions during 21 days immersion of GP and PC pastes.

Fig. 10 displays the evolution of the $\mathrm{pH}$ of the $5 \%$ sulfuric acid solutions during 21 days of paste samples immersion. The initial $\mathrm{pH}$ of the $5 \%$ sulfuric acid solution was 0.89 . The $\mathrm{pH}$ of the acid solutions increases to approximately 3.0 during each exposure period for all GP and PC mixes. In consecutive exposure periods, the $\mathrm{pH}$ values decline gradually which suggests less leaching occurs over time. It is difficult to identify trends between different mixes because similar behaviour is observed for all mixes. 


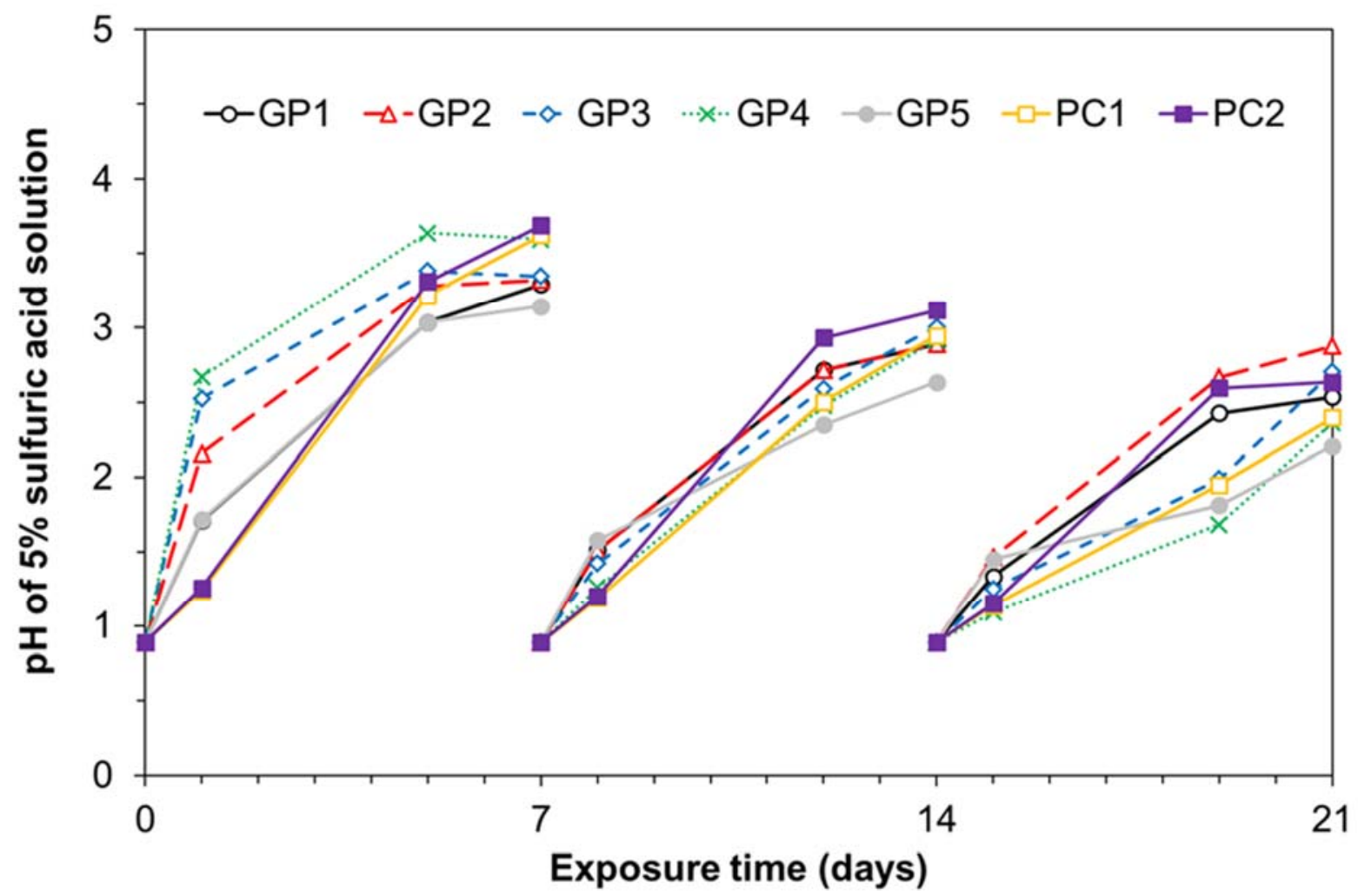

Fig. 10. $\mathrm{pH}$ of 5\% sulfuric acid solutions during 21 days immersion of GP and PC pastes.

Fig. 11 displays the cumulative concentration of aluminium, calcium, sodium, silicon, potassium, magnesium and iron in the water solutions during immersion of GP and PC pastes in water for 21 days. There were no significant quantities of aluminium, magnesium or iron present in the water solutions leached out from any of the GP or PC mixes (Fig. 11a, f and g). The main elements identified due to leaching from the GP mixes were sodium and silicon. This is not surprising due to the sodium silicate and sodium hydroxide solutions which were used as activators in the GP mixes. Furthermore, the mix with the increased activator dosage (GP5) resulted in a larger cumulative concentration of sodium $(4700 \mathrm{ppm})$ and silicon $(4100 \mathrm{ppm})$ in the water solutions after 21 days when compared with the other GP mixes. GP1-GP4 resulted in a cumulative sodium concentration of between 3000 and 3900 ppm in the water solution after 21 days. The cumulative silicon concentration in the water solution was lower than 1500 ppm after 21 days for GP1-GP4. Negligible concentrations of sodium and silicon were observed in the water solutions due to immersion of the PC mixes. Small potassium concentrations between 200 and 1000 ppm were observed for all mixes after 21 days. Finally, calcium concentrations of approximately $1500 \mathrm{ppm}$ were observed for the PC mixes while negligible concentrations were observed for the GP mixes. 

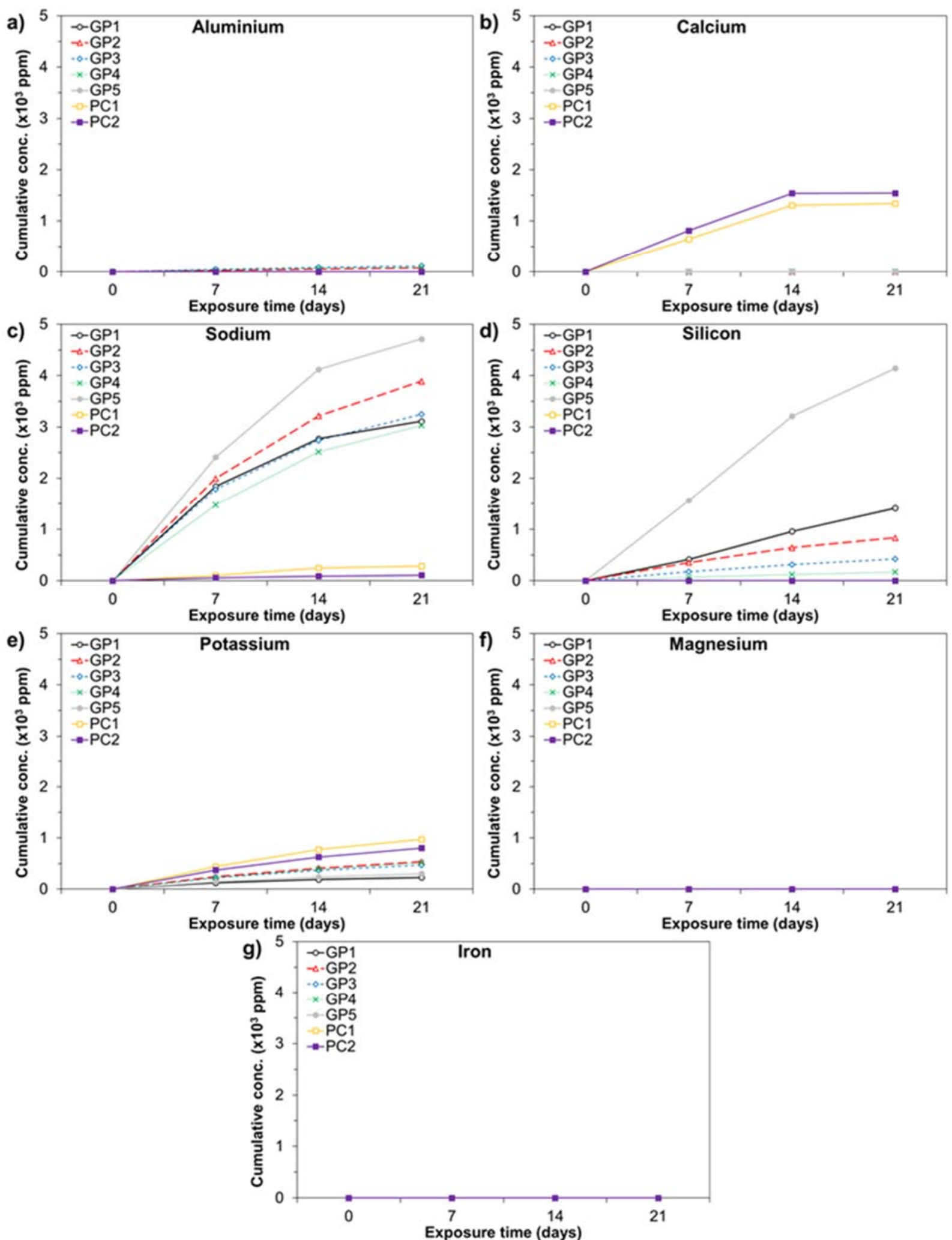

Fig. 11. Cumulative concentration of aluminium, calcium, silicon and sodium leached into water during 21 days exposure of GP and PC pastes to water.

Fig. 12 displays the cumulative concentrations of aluminium, calcium, sodium, silicon, potassium, magnesium and iron in the sulfuric acid solutions during immersion of the GP and PC pastes in 5\% sulfuric acid for 21 days and is discussed below: 
- Aluminium: The concentration of aluminium leached out from the GP mixes increases during each exposure cycle. The 100\% fly ash mixes (GP5 and GP1) result in the highest final concentrations of 5100 and $4400 \mathrm{ppm}$, respectively. As the slag content increases, the aluminium concentrations decrease to 4100, 2800 and $2100 \mathrm{ppm}$ for GP2, GP3 and GP4, respectively. Smaller concentrations of aluminium were observed after exposure of the PC mixes to sulfuric acid. The aluminium concentrations observed for each mix are larger following sulfuric acid exposure compared with exposure to water (Fig. 11).

- Calcium: The cumulative concentration of calcium was approximately $1400 \mathrm{ppm}$ for all GP and PC mixes after 21 days, regardless of their initial calcium content. These values are similar to those observed for PC1 and PC2 during exposure to water indicating a saturation point may have been reached where the sulfuric acid solutions are no longer able to dissolve calcium.

- Sodium: The cumulative concentration of sodium due to the GP mixes is gradually decelerating with time suggesting that less sodium is released during each exposure period. The $100 \%$ fly ash mixes result in the largest sodium concentrations of 13100 and $12000 \mathrm{ppm}$ after 21 days for GP5 and GP1, respectively. As the slag content increases, the sodium concentrations decrease to 9900,7800 and 6500 ppm for GP2, GP3 and GP4, respectively. Smaller concentrations of sodium (200 ppm) were observed after exposure of the PC mixes to sulfuric acid. The GP mixes have much larger initial sodium content due to the sodium hydroxide and sodium silicate solutions used as alkaline activators. The only sodium source in the PC mixes is the raw PC which contains less than $1 \%$ sodium (Table 2).

- Silicon: The cumulative concentrations due to the GP mixes after 21 days are all between 500 and $1400 \mathrm{ppm}$. The PC mixes result in lower concentrations of approximately $300 \mathrm{ppm}$. These values are comparable with those observed following exposure to water. This suggests that sulfuric acid exposure causes preferential leaching of other elements before silicon.

- Potassium: The $100 \%$ fly ash mixes (GP1 and GP5) resulted in the highest cumulative potassium concentration of $2700 \mathrm{ppm}$. This is followed by GP2, GP3 and GP4 which resulted in cumulative concentrations of 2200, 1700, and 1300 ppm, respectively, after 21 days exposure to sulfuric acid. The PC mixes had cumulative concentrations of approximately 900 ppm. Overall, the concentrations of potassium leached out from each mix are relatively small due to the relatively small $(<5 \%)$ proportion of potassium in the raw materials (Table 2 ).

- Magnesium: The highest magnesium concentrations are observed due to GP4 (4900 ppm) followed by GP3 and GP2 (4000 and 2700 ppm, respectively). The $100 \%$ fly ash mixes (GP1 and GP5) resulted in cumulative concentrations of 1400 and 1200 ppm, respectively, after 21 days exposure. Therefore, as the slag content increases, the quantity of magnesium released 
into the sulfuric acid solution also increased. PC1 and PC2 resulted in cumulative concentrations of 1900 and $1700 \mathrm{ppm}$, respectively.

- Iron: The cumulative concentration of iron leached out from each mix increases during each exposure cycle. GP5 and GP1 result in the highest final concentrations of 2700 and $2200 \mathrm{ppm}$, respectively. As the slag content increases the iron concentrations decrease to 1300, 1200 and 900 ppm for GP2, GP3 and GP4, respectively. These values can be related to the initial iron composition of fly ash $(\sim 9 \%)$ and slag $(<1 \%)$ (Table 2$)$. Final cumulative concentrations of 600 and 100 ppm were observed due to PC1 and PC2. 

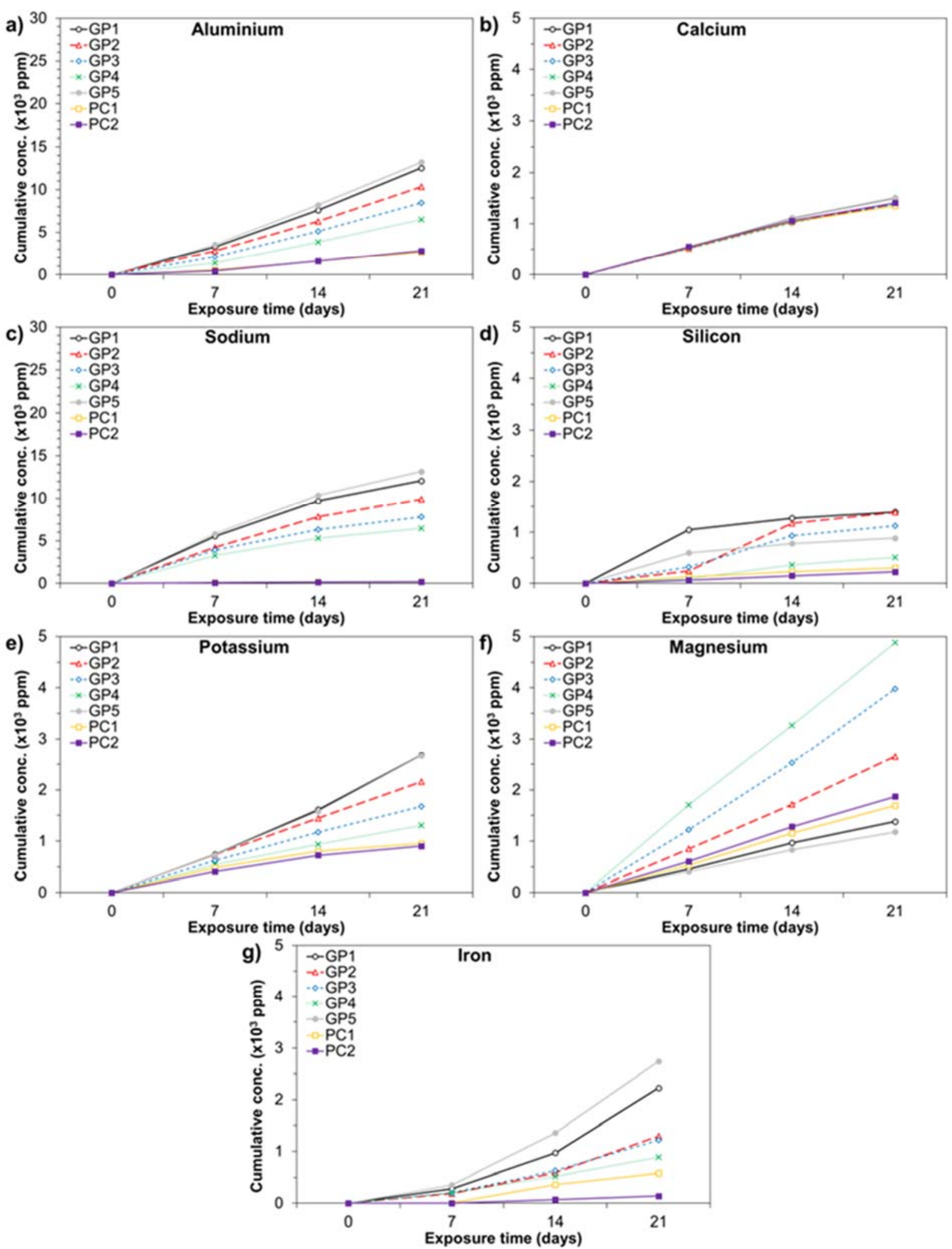

Fig. 12. Cumulative concentration of aluminium, calcium, silicon and sodium leached into sulfuric acid solutions during 21 days exposure of GP and PC pastes to 5\% sulfuric acid.

\subsection{X-ray diffraction (XRD)}

Fig. 13a displays the XRD patterns of the GP and PC pastes which were not exposed to acid attack. In the GP pastes, peaks of quartz $\left(\mathrm{SiO}_{2}\right)$ at $20.8,26.6,50.2$ and $60.0^{\circ} 2 \theta$, mullite $\left(\mathrm{Al}_{6} \mathrm{Si}_{2} \mathrm{O}_{13}\right)$ at 16.4, 26.0, 
$26.3,33.2,35.2,39.3,40.9,42.6$ and $60.7^{\circ} 2 \theta$ and hematite $\left(\mathrm{Fe}_{2} \mathrm{O}_{3}\right)$ at $35.6^{\circ} 2 \theta$ have been identified. The following powder diffraction files (PDF) were identified for quartz, mullite and hematite, respectively, PDF \# 01-085-0504, PDF \# 01-083-1881 and PDF \# 01-073-0603. These phases are present due to embedded unreacted fly ash particles [59] and are also identified in raw fly ash (Fig. 1). The intensity of these peaks is largest for the 100\% fly ash samples (GP1 and GP5) and decreases as the proportion of slag increases. The broad hump in the GP mixes between approximately 20 and $35^{\circ}$ $2 \theta$ indicates the presence of amorphous silicate and aluminosilicate gel phases [60], [61]. In the GP mixes which contain slag (GP2, GP3 and GP4), a large broad peak is observed at approximately $29^{\circ}$ $2 \theta$. This peak has been reported as poorly crystalline calcium silicate hydrate (C-S-H) type gel and the intensity increases as the proportion of slag increases [62]-[65]. In this case, the gel is likely to be CA-S-H gel or C-N-A-S-H gel [56]. C-N-A-S-H is a hybrid of C-A-S-H gel which is formed in slag systems [66] and N-A-S-H gel which is formed in fly ash systems [67]. The type of gel in each mix in this study is discussed in more detail in section 3.10 on SEM. The XRD patterns of the PC mixes before acid attack (Fig. 13a) highlight the presence of calcium hydroxide (PDF \# 01-075-0571), C-S$\mathrm{H}$, ettringite (PDF \# 00-041-1451) and semicarbonate. Calcium hydroxide is identified by peaks at $18.1,34.1,28.7,47.1,50.8,54.4$ and $62.6^{\circ} 2 \theta$. The main ettringite peaks were located at 9.1, 15.8, 18.9 and $22.9^{\circ} 2 \theta$. Semicarbonate is an AFm phase identified by a peak at $10.8^{\circ} 2 \theta$ [68], [69]. AFm is notation for a family of hydrated calcium aluminate phases occurring in hydrated cement paste [68], [70].

Fig. 13b displays the XRD patterns of the GP and PC pastes after they were exposed to $5 \%$ sulfuric acid for 21 days. The GP samples demonstrated the presence of gypsum (calcium sulphate hydrate, PDF \# 01-074-1905). Increased intensity of the gypsum peaks was observed as the slag content increased. Mullite, quartz and hematite phases were identified in the 100\% fly ash samples (GP1 and GP5). As reported by Bellmann and Stark [71], the quartz and gypsum peaks at 20.8 and $20.9^{\circ} 2 \theta$, respectively, can be difficult to distinguish. However, on close inspection, a double peak was observed indicating the presence of both quartz and gypsum. Mullite, quartz and hematite phases were difficult to identify in the samples containing slag (GP2, GP3, and GP4) with small peaks due to mullite and quartz visible in GP2. The broad peak at approximately $29^{\circ} 2 \theta$ was no longer present in the pastes containing slag (GP2, GP3 and GP4) after exposure to sulfuric acid. This suggests that the C-A-S-H and C-N-A-S-H gel is vulnerable to sulfuric acid attack. The PC pastes showed significant changes to their XRD patterns after exposure to sulfuric acid. The peaks attributed to calcium hydroxide, C-S-H, ettringite and semicarbonate were no longer present following acid exposure suggesting they are susceptible to sulfuric acid attack. Gypsum was the only phase identified in the outside layer of the PC samples attacked by sulfuric acid. The main gypsum peaks were located at 11.7, 20.7, 29.1, 31.1, 33.4, 40.7, 43.3 and $56.8^{\circ} 2 \theta$. 

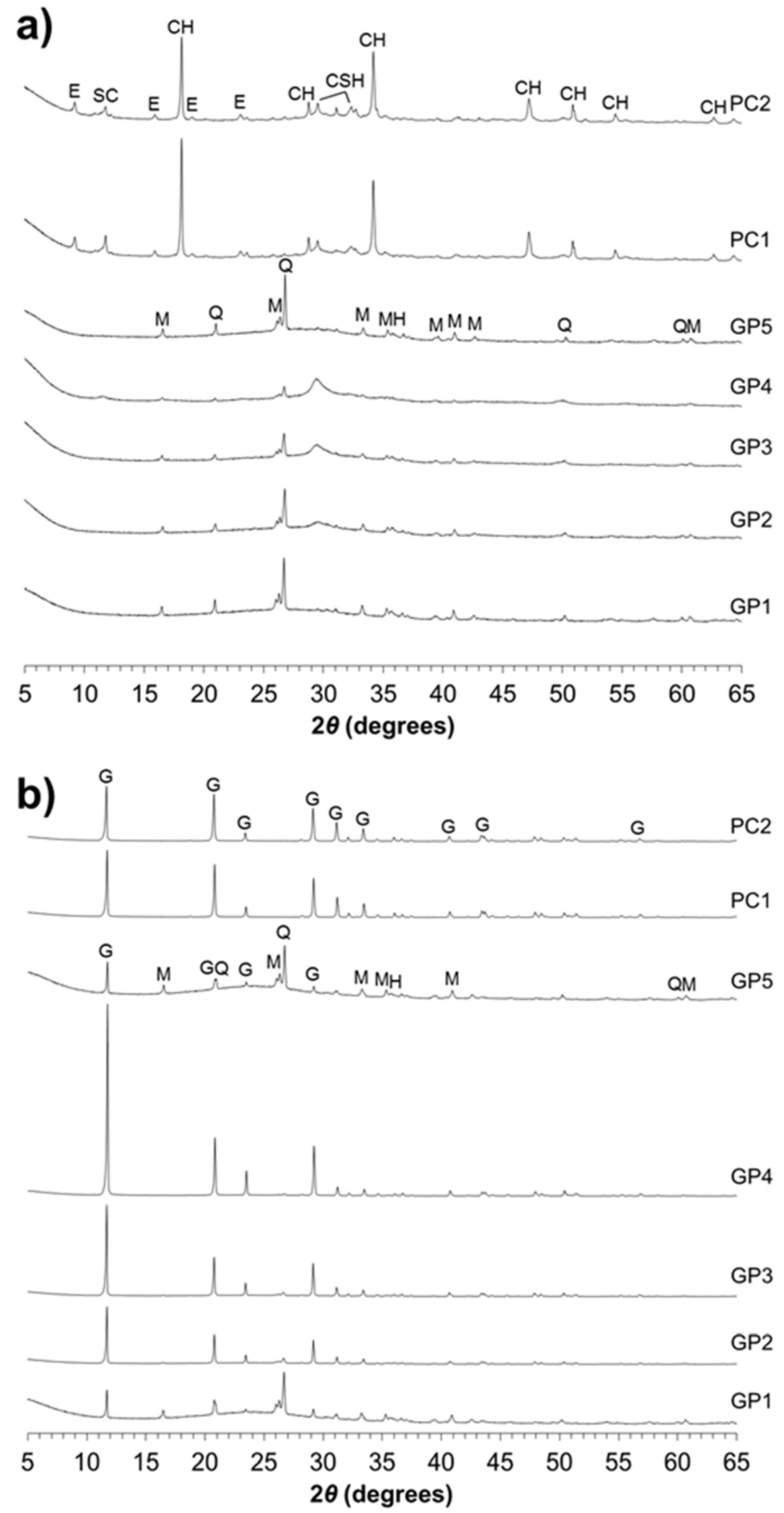

Fig. 13. XRD patterns of GP and PC pastes, a) control samples not exposed to acid and b) after 21 days of exposure to sulfuric acid (M - mullite, Q - quartz, H - hematite, E - ettringite, SC semicarbonate, $\mathrm{CH}$ - calcium hydroxide, $\mathrm{CSH}$ - calcium silicate hydrate, $\mathrm{G}$ - gypsum). 


\subsection{Thermogravimetric analysis (TGA)}

Fig. 14 displays the TGA data for the GP and PC pastes which were not exposed to acid, showing final mass losses between 8 and $23 \%$ after heating to $1000{ }^{\circ} \mathrm{C}$. The differential thermal analysis (DTG) is shown in Fig. 15. It is worth noting that the GP pastes have no significant mass losses after approximately $200{ }^{\circ} \mathrm{C}$ which suggests that they mainly consist of amorphous gels with physically and chemically bound water [72]. The main mass loss for all samples occurs at approximately $100{ }^{\circ} \mathrm{C}$, partly due to the evaporation of free water below $100{ }^{\circ} \mathrm{C}$ [61] which is considered to be completely removed at $120{ }^{\circ} \mathrm{C}$ [73]. The main weight loss due to moisture within C-S-H type gel (GP and PC mixes) occurs between 50 and $200{ }^{\circ} \mathrm{C}$ [74] and the loss of water within N-A-S-H gel (GP mixes) is reported to occur at around $100{ }^{\circ} \mathrm{C}$ [75]. Therefore, mass losses due to moisture within C-S-H type and $\mathrm{N}-\mathrm{A}-\mathrm{S}-\mathrm{H}$ gels may also contribute to the main peaks observed at approximately $100{ }^{\circ} \mathrm{C}$. The smallest overall mass loss is observed for GP1, with the main peak centred at $129{ }^{\circ} \mathrm{C}$. The main peak for the other $100 \%$ fly ash mix (GP5) is centred at the same temperature. The mass loss observed for these mixes may be small due to the curing conditions employed; these samples were cured at $70{ }^{\circ} \mathrm{C}$ for 7 days which means a large portion of the free evaporable moisture would have been removed during curing. This explains why GP1 and GP5 display small mass losses (approximately 8 and 13\%, respectively) and why the peak was centred at a higher temperature. Similar behaviour was reported by Ismail et al. [76] when alkali activated pastes were exposed to drying at $60{ }^{\circ} \mathrm{C}$. The fly ash/slag mixes (GP2, GP3 and GP4) display increasing mass loss (Fig. 14) as the slag content increases. This may be due to formation of more C-A-S-H/C-N-A-S-H gel, therefore, more bound water [56]. The mass losses for the GP pastes begin to plateau after approximately $250^{\circ} \mathrm{C}$, whereas the $\mathrm{PC}$ pastes have further mass losses at higher temperatures. Three main peaks are identified for the PC mixes. The first peak occurs at approximately $100{ }^{\circ} \mathrm{C}$. As previously mentioned this peak can be related to removal of evaporable moisture and partially to the removal of moisture from C-S-H gel. Ettringite decomposition can take place between 114 and $116{ }^{\circ} \mathrm{C}$ [77], [78], though it is more likely to occur at lower temperatures depending on the humidity conditions [79]. Therefore, the decomposition of ettringite may also contribute to the first peak at $c a .100{ }^{\circ} \mathrm{C}$. The second peak occurs at $146{ }^{\circ} \mathrm{C}$ for both PC mixes, which can be related to AFm phases such as semicarbonate [80]-[82]. The third peak is observed at 449 and $446{ }^{\circ} \mathrm{C}$ for PC1 and PC2, respectively. Peaks detected at these temperatures can be attributed to the presence of calcium hydroxide [83]-[85].

The DTG of the GP and PC pastes after exposure to 5\% sulfuric acid is displayed in Fig. 15b. GP1 and GP5 have a peak at $123{ }^{\circ} \mathrm{C}$ which may be related to N-A-S-H gel, but also an additional peak at 63 and $86{ }^{\circ} \mathrm{C}$, respectively. The fly ash and slag blends (GP2, GP3 and GP4) also have an additional peak which is centred at approximately $70{ }^{\circ} \mathrm{C}$. These peaks located between 63 and $86{ }^{\circ} \mathrm{C}$ are likely due to the removal of loosely bound moisture which was not removed during preparation of the powdered sample ( 24 hours at $35{ }^{\circ} \mathrm{C}$ in a desiccator). An additional peak is also observed at approximately 136 
${ }^{\circ} \mathrm{C}$ (GP2, GP3 and GP4) and the PC samples have a single peak at $134{ }^{\circ} \mathrm{C}$. These peaks are believed to be due to gypsum. The main decomposition of gypsum takes place between approximately 100 and $170{ }^{\circ} \mathrm{C}$ [73], [86] or more specifically between 130 and $150{ }^{\circ} \mathrm{C}$ [87]. The mass loss due to gypsum appeared largest for the PC mixes followed by GP4, GP3 and GP2. This suggests that as the slag content increased, the quantity of gypsum produced also increased. Similar to XRD analysis of the PC samples, the peaks due to C-S-H, ettringite, semicarbonate and calcium hydroxide are not present after sulfuric acid exposure (Fig. 15b).

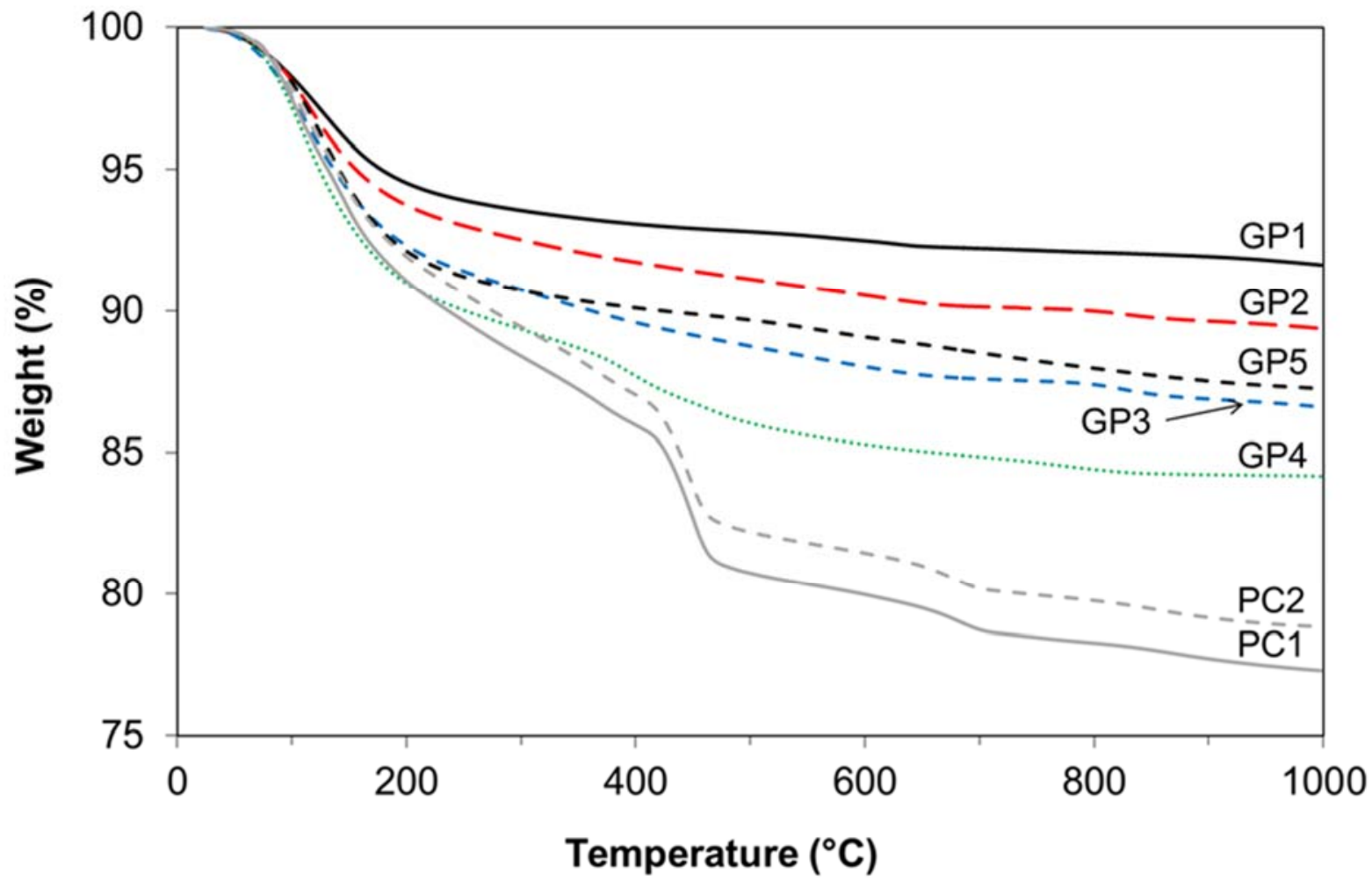

Fig. 14. Thermogravimetric data of GP and PC pastes not exposed to acid. 
a)

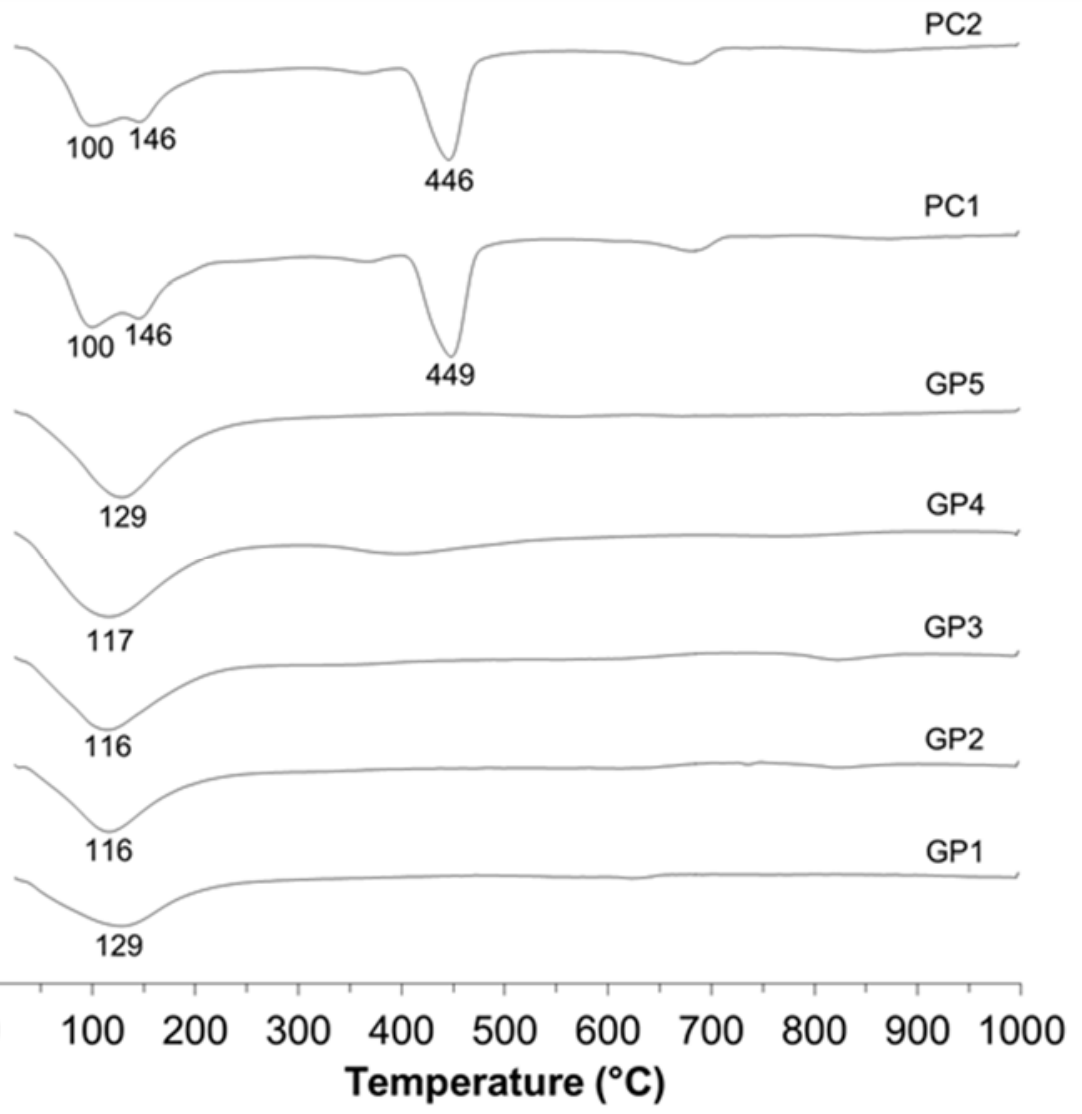

b)

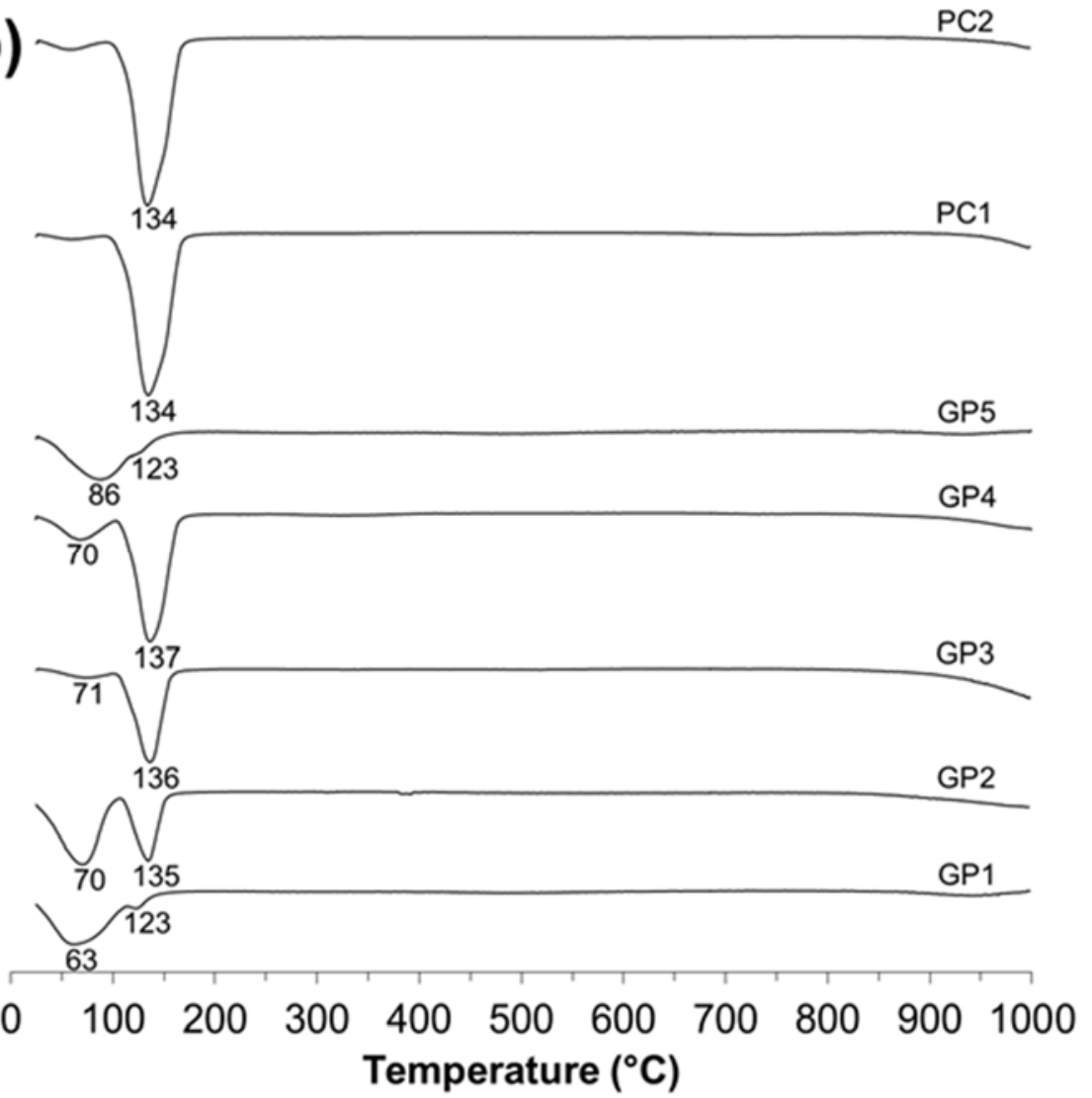

Fig. 15. Differential thermogravimetric analysis (DTG) of GP and PC pastes, a) control samples not exposed to acid and $b$ ) after 21 days of exposure to sulfuric acid. 


\subsection{Fourier transform infrared spectroscopy (FTIR)}

The FTIR spectra for the GP and PC pastes not exposed to acid are presented in Fig. 16a. The bands at approximately 1640 and $3400 \mathrm{~cm}^{-1}$ are due to vibrations of $\mathrm{OH}$ and $\mathrm{H}-\mathrm{O}-\mathrm{H}$ groups from water molecules [72], [88]-[91]. These bands indicate the presence of water molecules due to crystallisation or absorption of reaction products [92]. The strongest vibration occurs between wavenumbers of 953 and $997 \mathrm{~cm}^{-1}$ and is assigned to asymmetrical $\mathrm{T}-\mathrm{O}$ stretch vibrations $(\mathrm{T}=\mathrm{Si}$ or $\mathrm{Al})$ and can be related to the type of gel present in the samples [30], [93]. Garcia-Lodeiro et al. [94] suggested that when the peak is centred at approximately $970 \mathrm{~cm}^{-1}, \mathrm{C}-\mathrm{S}-\mathrm{H}$ type gel is likely to be present and when it is centred at approximately $1000 \mathrm{~cm}^{-1}$, N-A-S-H gel is likely to be present. This suggests that the $100 \%$ fly ash samples (GP1 and GP5) contain N-A-S-H gel compared with C-S-H type gel in the samples containing slag (GP2, GP3 and GP4) and the PC samples. However, it is likely that the gel present in samples GP2, GP3 and GP4 which are blends of fly ash and slag is C-A-S-H or a hybrid form of C-AS-H and N-A-S-H, namely C-N-A-S-H [56], [67], [95]. The type of gel present in these mixes is discussed in more detail in section 3.10 on SEM. A small narrow band at $3635 \mathrm{~cm}^{-1}$ is related to stretching vibrations produced by O-H bonds in calcium hydroxide [66], [96]. This band can be identified in PC1 and PC2 indicating the presence of calcium hydroxide. Calcium hydroxide was not identified in the GP samples as also reported by XRD and TGA. A small shoulder at $1105 \mathrm{~cm}^{-1}$ corresponding to asymmetric stretching vibrations of sulphate in ettringite [37], [97] was also identified in PC1 and PC2 which is also in agreement with XRD and TGA.

Fig. 16b displays the FTIR spectra for the GP and PC pastes after exposure to 5\% sulfuric acid. The main difference after sulfuric acid exposure compared with the unexposed samples (Fig. 16a) is the shifting of the main peak to higher wavenumbers. The main peak for GP1 and GP5 has shifted to 1068 and $1066 \mathrm{~cm}^{-1}$, respectively, indicating that the $\mathrm{Si} / \mathrm{Al}$ ratio is higher in the samples exposed to acid and can be attributed to dealumination of the binding gel resulting in a highly siliceous gel being left behind [98]. In GP1 and GP5, the bands at approximately 1640 and $3400 \mathrm{~cm}^{-1}$ due to vibrations of OH and $\mathrm{H}-\mathrm{O}-\mathrm{H}$ groups from water molecules were not altered by acid exposure. However, these bands were no longer present in GP2, GP3, GP4, PC1 and PC2 after sulfuric acid exposure. The main peak of the fly ash and slag blends (GP2, GP3 and GP4) shifted to approximately $1110 \mathrm{~cm}^{-1}$ which can be attributed to the presence of gypsum [31], [99]-[102]. Another peak was identified at approximately $670 \mathrm{~cm}^{-1}$ which is also attributed to gypsum [99], [102], [103]. Additionally, peaks at approximately 1621 and $1684 \mathrm{~cm}^{-1}$ are also associated with the presence of gypsum [31]. Finally, double peaks at approximately 3410 and $3530 \mathrm{~cm}^{-1}$ are also related to the presence of gypsum [99], [102], [104], [105]. These peaks related to gypsum are observed for the PC pastes as well as the fly ash and slag blends (GP2, GP3 and GP4). The GP pastes also exhibit a peak at approximately $795 \mathrm{~cm}^{-1}$ after exposure to acid. This peak can be assigned to the presence of quartz in unreacted fly ash particles which remain embedded after activation. It is more readily identifiable after acid exposure due to the intense acid 
attack which has removed the reaction products of alkali-activation [106], [107]. GP1 and GP5 have the largest peak in this region which decreases as the proportion of slag increases. In the case of PC1 and PC2 the small peak at $3635 \mathrm{~cm}^{-1}$ due to calcium hydroxide was no longer observed suggesting it has been attacked by sulfuric acid in agreement with the results obtained by XRD and TGA. Similarly, the shoulder at $1105 \mathrm{~cm}^{-1}$ is no longer present suggesting ettringite has also been removed due to sulfuric acid exposure. 
a)

$\mathrm{PC} 2$

$3635^{\pi} 340016401105_{960}^{\pi}$

PC1

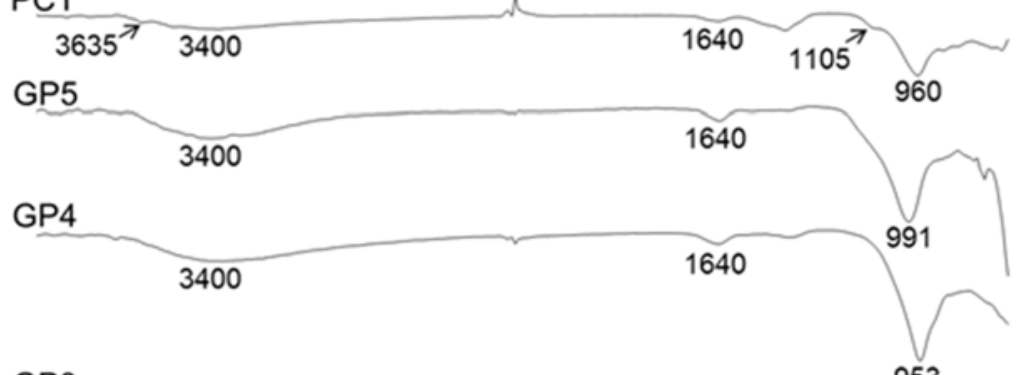

GP3

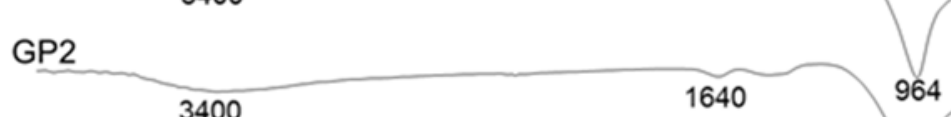

GP1 970

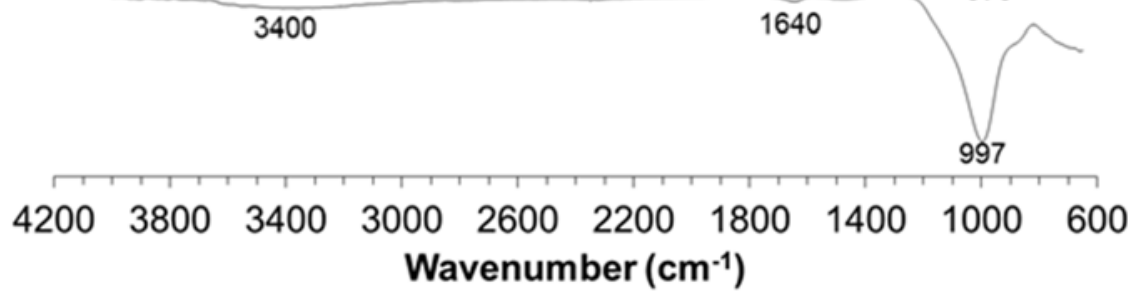

b) $\frac{P C 2}{35333408} 16841621$

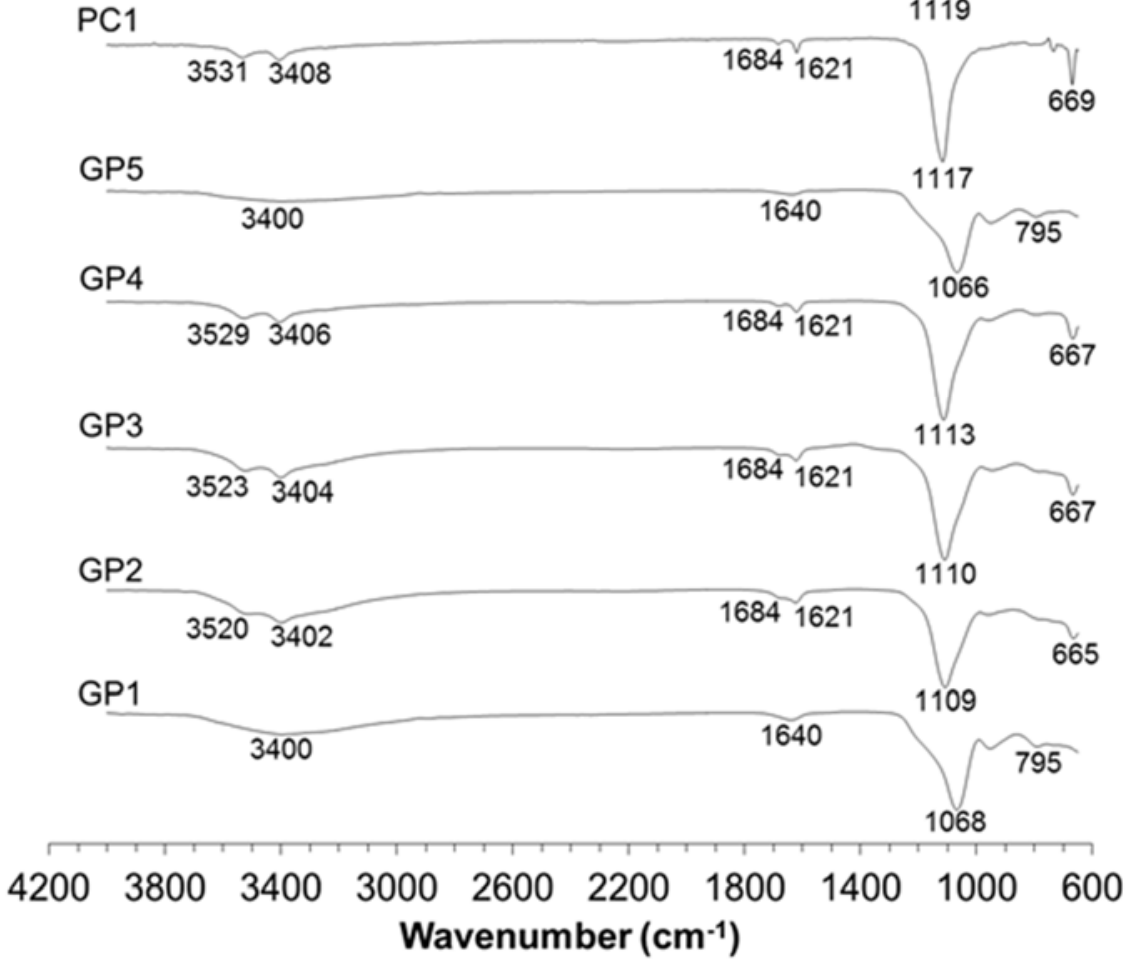

Fig. 16. FTIR spectra of GP and PC pastes, a) control samples not exposed to acid and b) after 21 days of exposure to sulfuric acid. 


\subsection{Scanning electron microscopy (SEM) and energy dispersive X-ray (EDX) analysis}

The paste mixes were examined before acid attack using point analysis to obtain the composition of the main binder gel in each sample. The $\mathrm{Ca} / \mathrm{Si}$ and $\mathrm{Al} / \mathrm{Si}$ ratios can indicate the type of gel present and the average values and standard deviation are presented in Table 4. For each mix, a minimum of 10 points were analysed. The fly ash samples (GP1 and GP5) have a Ca/Si ratio of approximately 0.10 which indicates the presence of N-A-S-H gel. As the slag content increases, the $\mathrm{Ca} / \mathrm{Si}$ ratio also increases due to the higher initial calcium content in slag (Table 2). Therefore, as the slag content increases, C-N-A-S-H and C-A-S-H gels are present instead of N-A-S-H gel [56], [108], [109]. The high $\mathrm{Ca} / \mathrm{Si}$ ratio for the $\mathrm{PC}$ samples can be explained by the coexistence of $\mathrm{C}-\mathrm{S}-\mathrm{H}$ gel and calcium hydroxide [110]. The Al/Si ratio is similar for each of the GP mixes $(0.28$ to 0.37$)$ and smaller for the PC mixes (0.10 and 0.12).

Table $4 \mathrm{Ca} / \mathrm{Si}$ and $\mathrm{Al} / \mathrm{Si}$ atomic mass ratios of GP and PC pastes obtained from EDX analysis with standard deviation given in brackets.

\begin{tabular}{ccc}
\hline \multirow{2}{*}{ Paste ID } & \multicolumn{2}{c}{ Atomic mass ratios } \\
\cline { 2 - 3 } & $\mathrm{Ca} / \mathrm{Si}$ & $\mathrm{Al} / \mathrm{Si}$ \\
\hline \multirow{2}{*}{ GP1 } & 0.10 & 0.33 \\
& $(0.01)$ & $(0.01)$ \\
\hline \multirow{2}{*}{ GP2 } & $\mathbf{0 . 5 9}$ & $\mathbf{0 . 3 2}$ \\
& $(0.03)$ & $(0.02)$ \\
\hline \multirow{2}{*}{ GP3 } & $\mathbf{0 . 7 7}$ & $\mathbf{0 . 3 7}$ \\
& $(0.10)$ & $(0.04)$ \\
\hline \multirow{2}{*}{ GP4 } & 1.08 & $\mathbf{0 . 2 8}$ \\
& $(0.03)$ & $(0.04)$ \\
\hline \multirow{2}{*}{ GP5 } & $\mathbf{0 . 0 9}$ & $\mathbf{0 . 3 7}$ \\
& $(0.01)$ & $(0.04)$ \\
\hline \multirow{2}{*}{ PC1 } & $\mathbf{2 . 9 5}$ & $\mathbf{0 . 1 0}$ \\
& $(0.28)$ & $(0.02)$ \\
\hline \multirow{2}{*}{ PC2 } & $\mathbf{3 . 2 3}$ & $\mathbf{0 . 1 2}$ \\
& $(0.15)$ & $(0.02)$ \\
\hline
\end{tabular}

Fig. 17 displays the outside layer and elemental analysis of GP1, GP4 and PC2 after exposure to 5\% sulfuric acid for 21 days. GP1, GP4 and PC2 were chosen to have a comparison of one mix from each of the three binder types used in this study, namely $100 \%$ fly ash, fly ash/slag blends and PC mixes. The SEM images display approximately the outside $2 \mathrm{~mm}$ layer of each mix and the elemental composition in this region is also analysed.

Fig. 17a displays the outside layer of GP1, numerous cracks are visible, most of which are perpendicular to the exposed face. However, despite the cracks, the edge of the sample appears to remain relatively undamaged. The calcium within GP1 appears in small clusters and sulphur is also 
observed in these clusters which suggest the presence of small quantities of gypsum. These are often found inside hollow fly ash particles as shown in Fig. 18. Based on the elemental analysis, it appears that sulfuric acid has penetrated beyond the outside $2 \mathrm{~mm}$ of GP1 shown in Fig. 17a because there is no variation of the intensity of the analysed elements in this region. This seems reasonable considering the alkalinity losses reported in section 3.5 for the corresponding mortar mixes.

Fig. 17b displays GP4 after attack by sulfuric acid. There are three clear layers of attack, one corresponding to each replenishment of the acid solution. The elemental analysis shows that there are three layers of gypsum crystals highlighted by the concentrated layers of calcium and sulphur. These layers of gypsum within the sample may act as a barrier to further attack. Following each layer of gypsum, there is a darker in colour highly siliceous layer of GP paste that has a lack of calcium which has been consumed to form gypsum. At the top of Fig. 17b, a layer which appears relatively unaffected by acid attack can be observed. There are reasonable amounts of aluminium and sodium present in this layer in comparison with the outer layers where the aluminium and sodium have been depleted and leached into the acid solution as previously identified in Fig. 12. The majority of the visible cracks in GP4 after sulfuric acid attack are parallel to the exposed face, which is likely due to the internal stresses caused by the formation of the gypsum layers. It also appears that some material has been removed from the sample edge, but unclear to what extent.

Fig. 17c displays PC2 after attack by sulfuric acid. There are two main layers, the outside layer which appears visibly deteriorated and an inner layer which seems relatively unaffected by acid attack. The outside layer has significant amounts of calcium and sulphur, indicating the presence of gypsum. The gypsum crystals are not easily identified in Fig. 17c but are visible at higher magnification presented in Fig. 19, which is an SEM image from within the outside layer. The location of the image in Fig. 19 is shown by the box in Fig. 17c. Similar to GP4 after sulfuric acid attack, the majority of visible cracks are parallel to the outside edge of the sample and are likely due to expansion stresses caused by the formation of gypsum. The outside edge of PC2 appears more vulnerable to loss of cement paste when compared with GP1 and GP4 (Fig. 17). Depletion of silicon and aluminium is also observed in the attacked layer of PC2. The distribution of sodium is not shown in PC2 as the sodium content is very low in PC (Table 2) and sodium based activators were not used in the PC mixes. Despite the depth of acid penetration appearing to be smaller for PC2 than GP4 in Fig. 17, it is not clear how much material has already been removed from PC2 due to the acid attack. The corresponding PC mortar mixes suffered significant mass losses due to sulfuric acid attack (Fig. 4). The alkalinity losses reported in section 3.5 for each mortar mix provides more details related to the depth of acid penetration for each mix. 

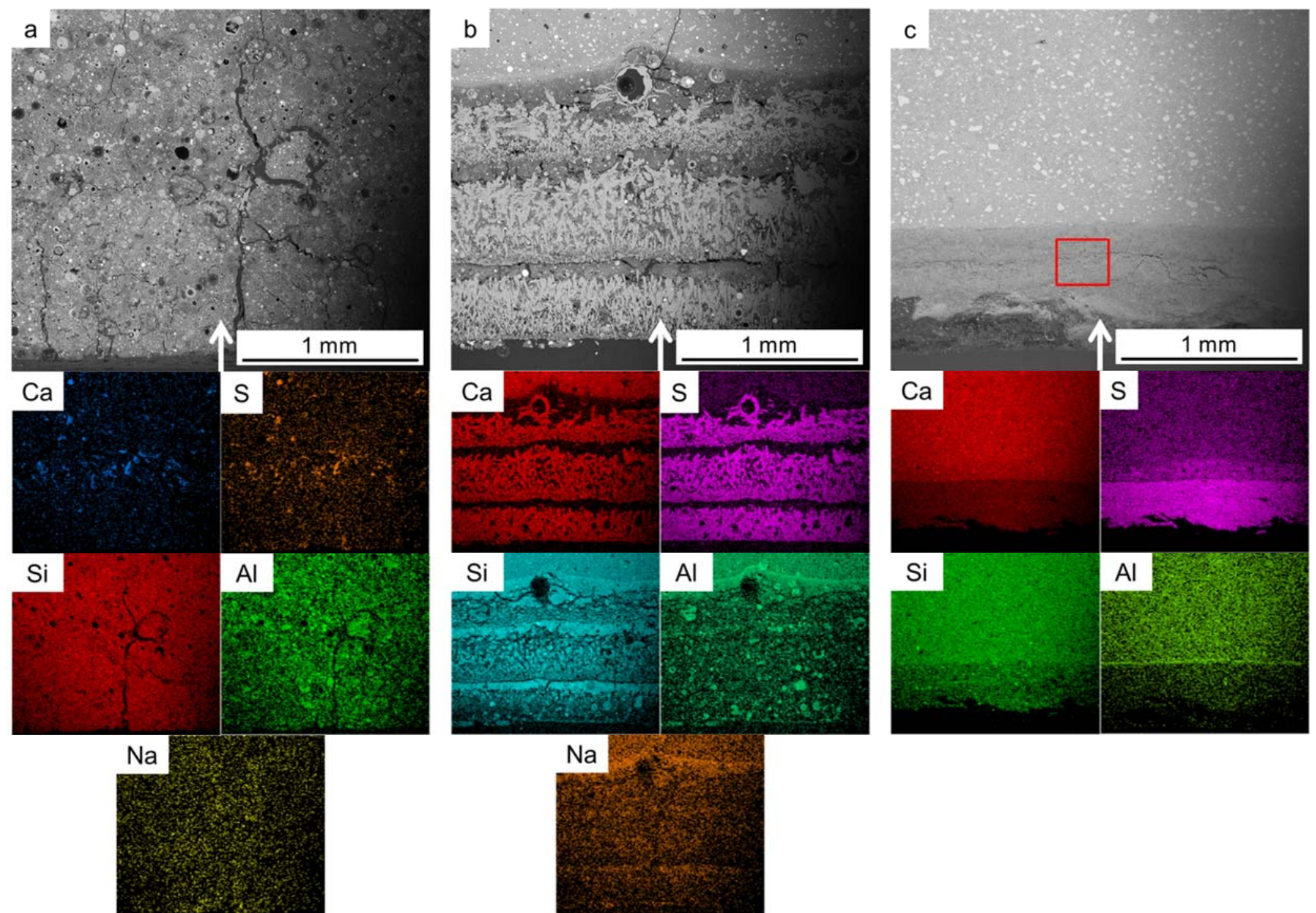

Fig. 17. SEM images of the outermost layer of a) GP1, b) GP4 and c) PC2 after exposure to sulfuric acid for 21 days (arrow showing direction of acid penetration). The elemental analysis shows the distribution of calcium (Ca), sulphur (S), silicon ( $\mathrm{Si}$ ), aluminium ( $\mathrm{Al}$ ) and sodium (Na). 

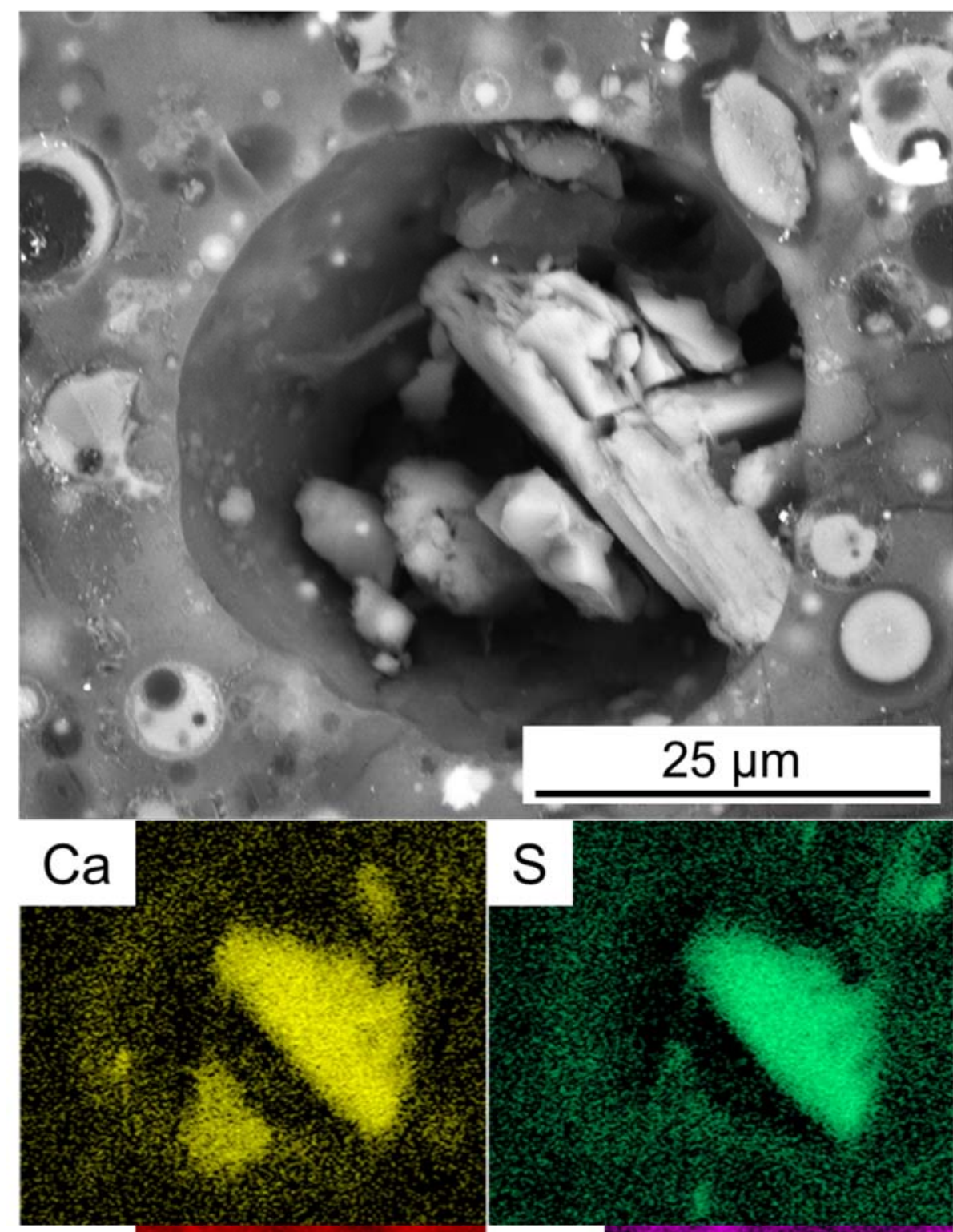

\section{$\mathrm{Si}$}
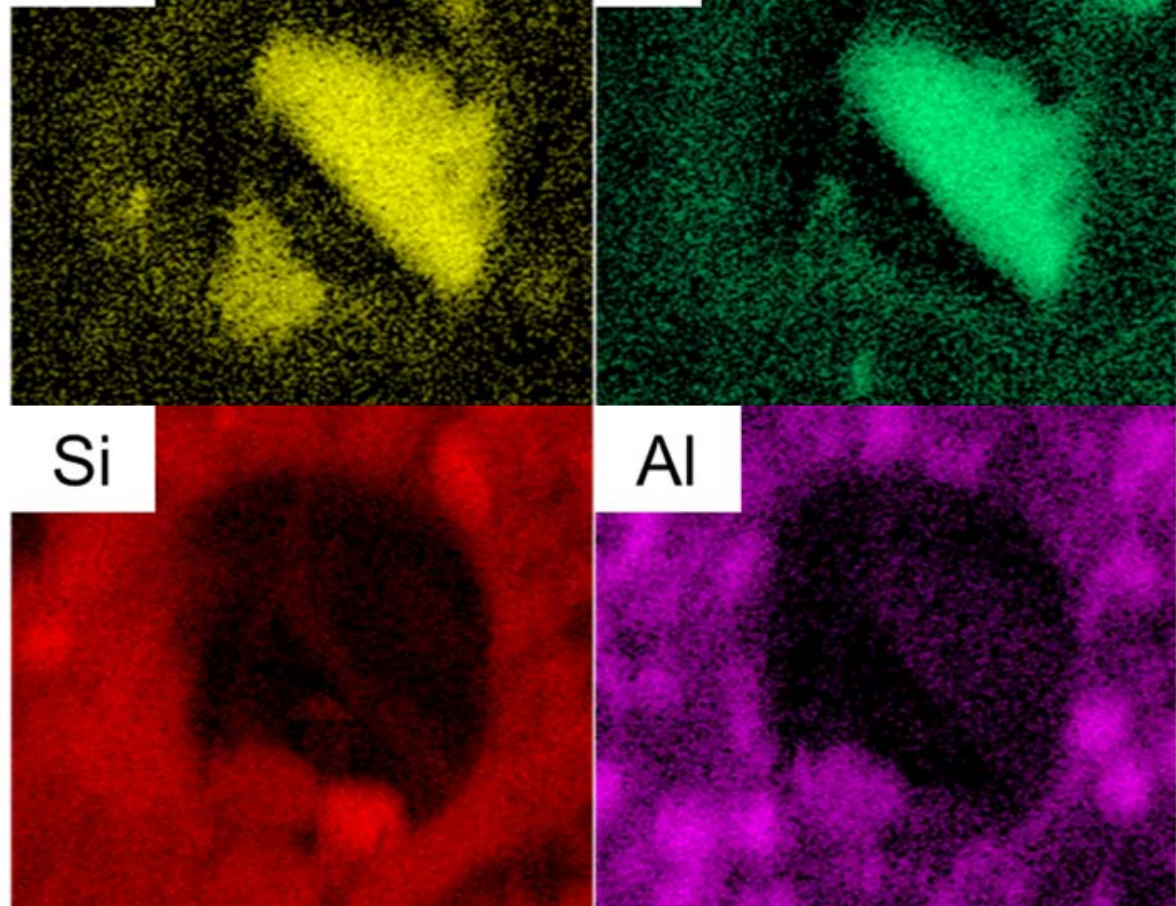

$\mathrm{Al}$

Fig. 18. SEM image of fly ash particle in GP1 after exposure to $5 \%$ sulfuric acid for 21 days with elemental analysis showing calcium (Ca), sulphur (S), silicon ( $\mathrm{Si}$ ) and aluminium (Al). 


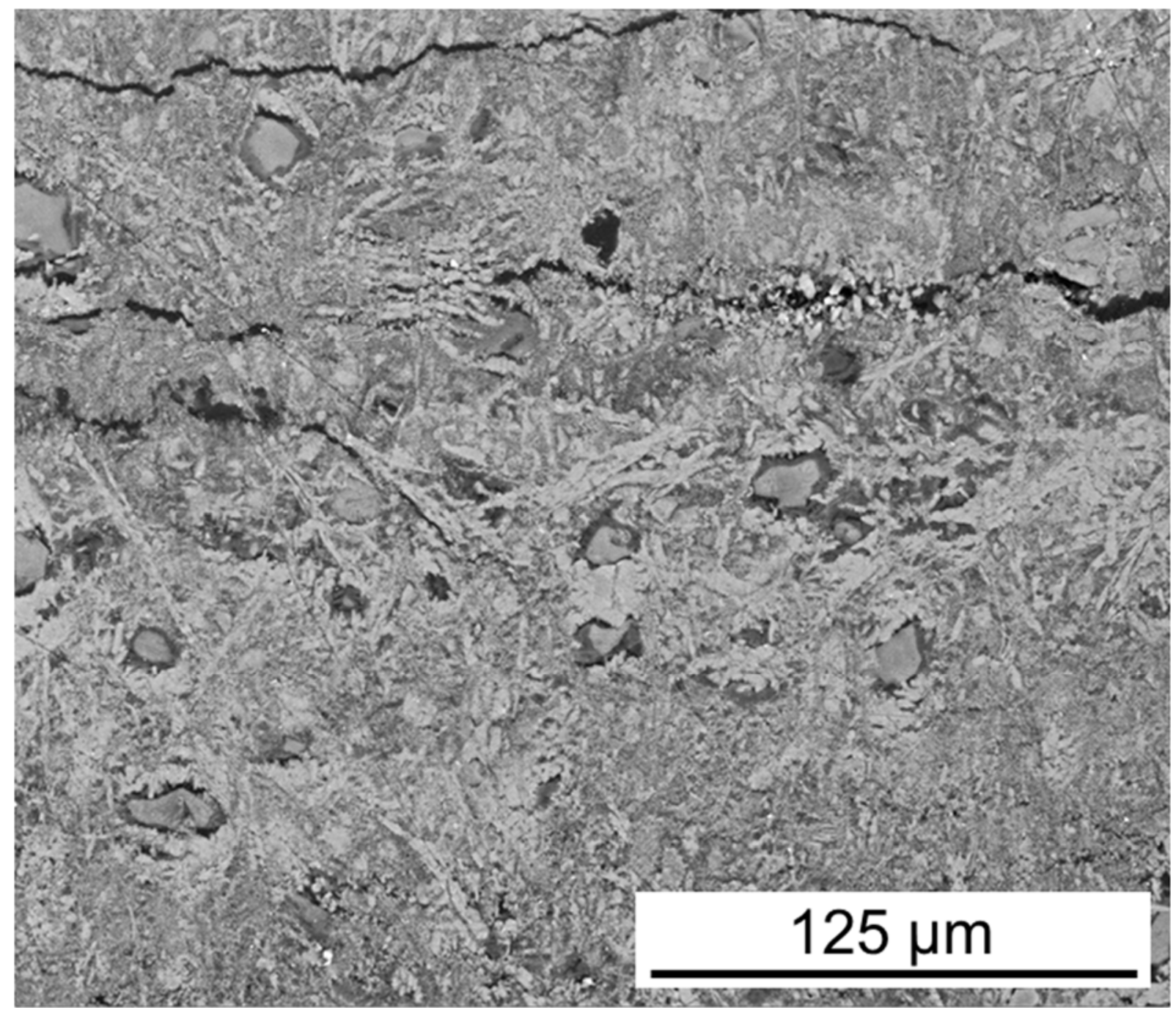

Fig. 19. SEM image of the outside layer of PC2 showing gypsum crystals.

\section{Discussion}

\subsection{Effect of increasing slag content}

As indicated by the visual examination (Fig. 3) of the mortars after 56 days exposure to sulfuric acid, GP1 showed very little visual damage and the amount of visible damage increased as the slag content increased with GP4 being the most visibly damaged. The damage was evident due to the removal of GP paste and the exposure of aggregates which was likely due to the dissolution of the GP paste caused by the acid attack. Cracks around the edge of GP4 were also observed which appear to indicate expansion and are similar to those observed by Aliques-Granero et al. [111] in alkali activated slag mortars. These cracks are likely due to the formation of gypsum which was identified by XRD, TGA, FTIR and EDX analysis. Gypsum is known to cause volumetric expansion by a factor of approximately 2.2 [13], [112]. The amount of gypsum formed was found to increase as the slag content increased (Fig. 13b) with the most gypsum forming in GP4, hence cracking occurred. Despite the visible damage increasing as the slag content increased, this was not reflected by the mass losses 
observed. The mass losses after 56 days exposure to $5 \%$ sulfuric acid were $3.5,7.6,3.3$ and $-0.1 \%$ for GP1, GP2, GP3 and GP4 respectively. This suggests that the mass losses observed were offset by the formation of gypsum which reduced the total mass loss, particularly for GP3 and GP4. Therefore, mass loss alone is not a suitable indicator of resistance to sulfuric acid attack for different binder materials. Similar findings have recently been observed by Gu et al. [113].

The alkalinity loss was found to decrease as the slag content increased (Figs. 7 and 8). GP1 had an alkalinity loss of $100 \%$ whereas GP4 had an alkalinity loss of $23 \%$ when exposed to $5 \%$ sulfuric acid. This is strongly correlated to the porosity values which were also found to decrease as the slag content increased (Fig. 2). As determined by SEM and EDX analysis GP1 contains N-A-S-H gel, which is more porous than space filling C-A-S-H/C-N-A-S-H gel [55], [60] present in GP4.

Corroded depth was reported as the most meaningful indictor of acid resistance by Lloyd et al. [32]. However, it is unclear how corroded the samples are despite evidence of penetration. GP1 has suffered the largest alkalinity loss, but there is less evidence of significant damage, whereas GP4 has had the smallest alkalinity loss but appears deteriorated further as demonstrated by visual appearance (Fig. 3), likely due to gypsum formation. Increasing the slag content also increases the compressive strength as previously reported by Puertas et al. [114]. However, the compressive strength does not seem to be the best indicator of acid resistance in these materials (Figs. 5 and 6) as no distinct trend is apparent in terms of the effect of slag content on compressive strength loss. Rather the nature of the reaction products and pore structure seem to be more significant.

Increasing the slag content reduced the resistance of the reaction products to sulfuric acid. The resulting binder gel has higher calcium content, therefore more gypsum can be formed which results in internal stresses due to expansion. On the other hand, increasing the slag content improved the pore structure, resulting in a reduced porosity, which provides more resistance to ingress of acid.

The mechanism of sulfuric acid attack has been illustrated schematically for GP and PC mixes in Fig. 20. In all four mixes (GP1, GP2, GP3 and GP4) the mechanism of attack appears to be similar whereby:

(1) Ion exchange takes place resulting in the transfer of sodium into the acid solution and the transfer of $\mathrm{H}^{+}, \mathrm{H}_{3} \mathrm{O}^{+}$and $\mathrm{SO}_{4}{ }^{2-}$ into the samples.

(2) Almost simultaneously the hydrogen protons $\left(\mathrm{H}^{+}, \mathrm{H}_{3} \mathrm{O}^{+}\right)$attack the Si-O-Al bonds resulting in the ejection of aluminium into the acid solution leaving behind a highly siliceous framework [115], [116]. 
(3) Along with sodium and aluminium, smaller quantities of calcium, potassium, magnesium and iron are also transferred into the acid solution.

(4) The diffusing $\mathrm{SO}_{4}{ }^{2-}$ anions meet with counter diffusing calcium ions causing the deposition of gypsum crystals inside the penetrated layer. The amount of gypsum formed increases as the slag content increases. In the case of $100 \%$ fly ash (GP1), very little gypsum is formed due to the low calcium content. The formation of gypsum has a negative impact, it causes cracks and eventually leads to large fractures (GP4). 

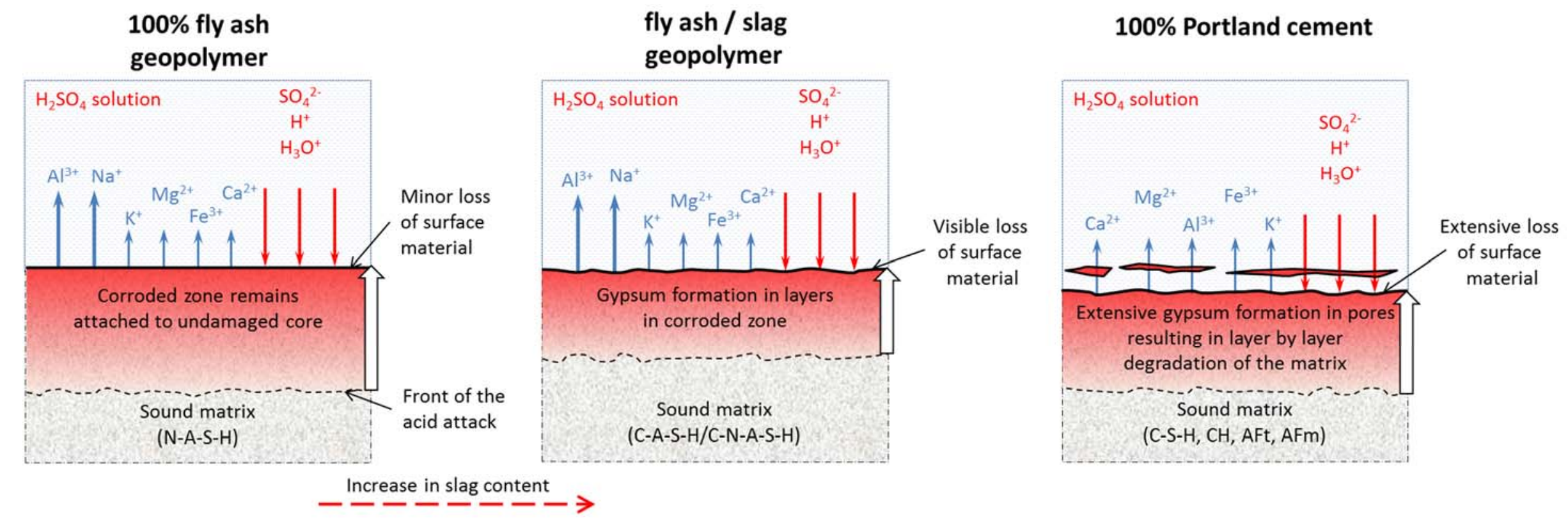

Fig. 20. Schematic diagram of the mechanism of sulfuric acid attack in $100 \%$ fly ash GPs, fly ash/slag GPs and $100 \%$ PC mixes 


\subsection{Effect of increased alkaline activator dosage}

The control mortar samples for GP1 had a compressive strength of $20 \mathrm{MPa}$ which increased to $55 \mathrm{MPa}$ for GP5. These values are similar to those reported by Soutsos et al. [117] when varying the alkaline activator dosages for fly ash GP mortars. GP5 had a lower porosity which is likely to be due to more complete activation of the fly ash taking place resulting in a denser microstructure [118]. Despite the increased compressive strength and reduced porosity there was no difference visually, by mass loss or by percentage compressive strength loss after exposure to sulfuric acid for 56 days. The alkalinity loss was $100 \%$ for GP1 but reduced to $82 \%$ for GP5, this can be attributed to the lower porosity (Fig. 2). The microstructural analysis displayed very little difference between GP1 and GP5 after acid exposure because the reaction products were similar. Only small amounts of gypsum were observed in GP1 and GP5 because very little calcium was available as fly ash contains much less calcium than slag (Table 2).

Overall increasing the alkaline activator dosage seems to have very little impact on the acid resistance of neat fly ash GPs. This is because the reaction products and mechanism of attack is similar for both as shown in Fig. 20. Therefore, the additional cost and environmental impact of using increased alkaline activator dosages is not worthwhile for acid resistance as very little increase in sulfuric acid resistance was observed. The only advantage is the reduced alkalinity loss which may be beneficial in structural applications when steel reinforcement is required.

\subsection{Comparison of GP and PC materials}

Visually the PC mortars were significantly more deteriorated than the GP mortars and they also displayed an increased mass loss, particularly for 5\% sulfuric acid. Interestingly, the mass loss for the PC mixes appears to be accelerating. However, for the GP samples the mass loss appears to be decelerating. This suggests the long term resistance of the GP mixes to sulfuric acid is much superior than that of PC mixes. The mass losses identified in the PC mixes are partly due to the dissolution of calcium hydroxide, which was no longer present after sulfuric acid attack as identified by XRD, TGA and FTIR. Calcium hydroxide is the first phase in PC to be attacked by acid and can begin to be removed at $\mathrm{pH}$ values below 12.5 [119]-[121]. These mass losses are also due to the dissolution of ettringite and AFm phases, such as semicarbonate, which was also observed in the PC mixes by XRD, TGA and FTIR after acid attack. Furthermore, the decalcification of C-S-H was detected which alongside the dissolution of calcium hydroxide results in a very porous corroded layer and a decrease in compressive strength [122]-[124]. On the other hand, the decalcification of the C-A-S-H and/or CN-A-S-H type gel present in GP2, GP3 and GP4 results in a dense highly siliceous layer which is more resistant to further acid attack [110], [125], [126]. The calcium, which has been removed from various phases in the PC mixes reacts with sulfuric acid to form gypsum which causes expansion and 
softening of the cement paste [127]. Greater amounts of gypsum are formed in the PC mixes due to the higher initial calcium content when compared with GP mixes.

Fig. 21 displays the relationship between the mass loss and alkalinity loss for each mortar mix following exposure to $5 \%$ sulfuric acid for 56 days. The mixes behaviour can be grouped together into three main types i.e. $100 \%$ fly ash, fly ash/slag blends and PC mixes. In general, the $100 \%$ fly ash mixes have suffered smaller mass losses and larger alkalinity losses compared with the PC mixes for which the opposite is true. On the other hand, the fly ash/slag blends appear to offer a combination of good performance for both parameters. However, it is worth pointing out that the mass losses observed for the fly ash/slag blends have been affected by the formation of gypsum as discussed previously.

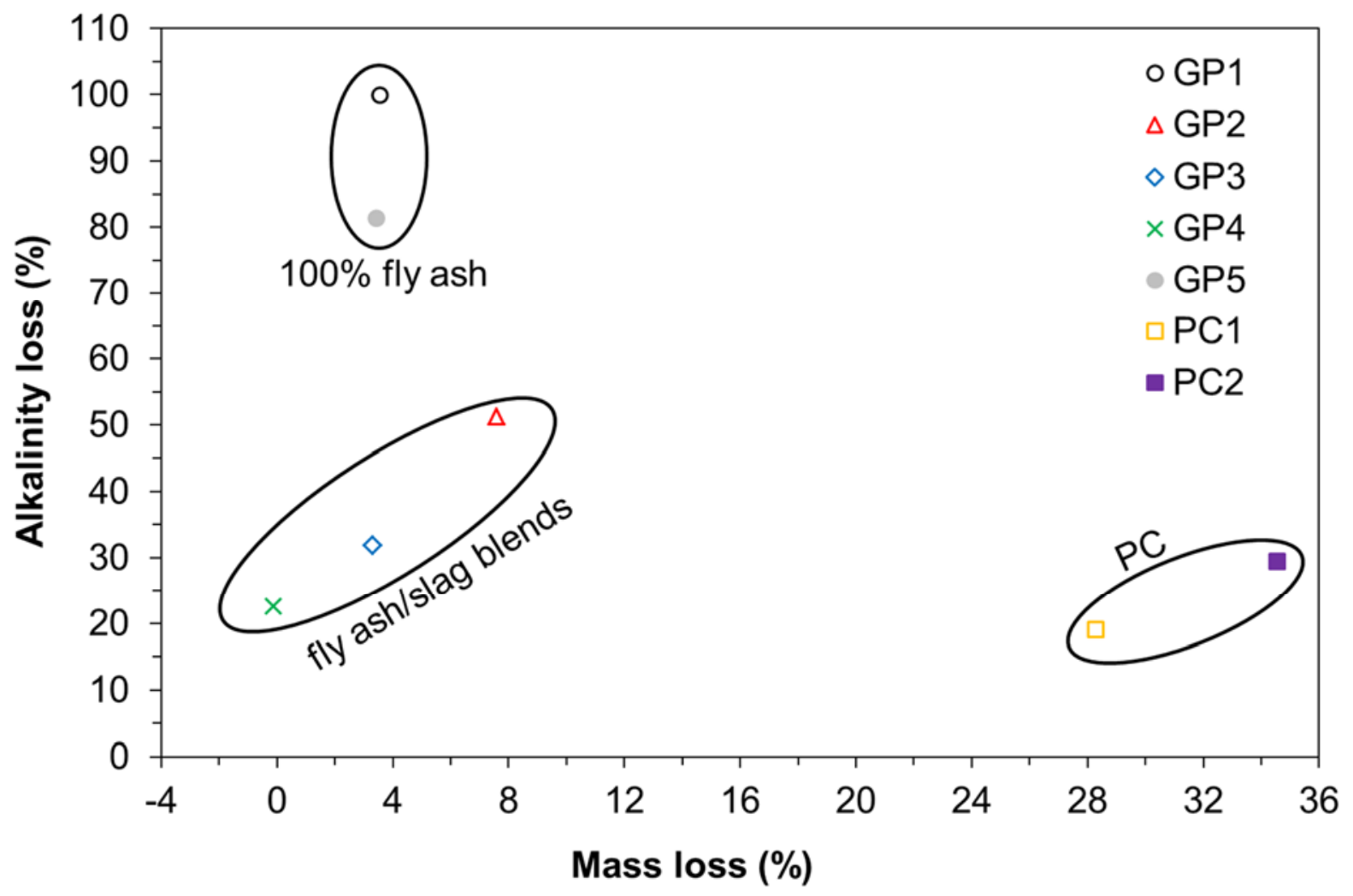

Fig. 21. Relationship between mass loss and alkalinity loss for GP and PC mortar mixes following 56 days exposure to $5 \%$ sulfuric acid.

The visual appearance, mass loss, alkalinity loss and SEM images show that the PC mixes deteriorate in a destructive fashion with the removal of highly corroded layers one after another. On the other hand, the GP mixes appear to withstand further acid penetration before damage is revealed. This is likely due to the greater amounts of gypsum formed in the PC mixes in contrast to the dense siliceous gel formed in the GP samples after sulfuric acid attack. Therefore, the nature of the main binding gel in GP mixes and the absence of calcium hydroxide, ettringite and AFm phases is a significant advantage for the sulfuric acid resistance of GP materials. 


\section{Conclusions}

In response to the outlined objectives the following conclusions have been made:

- Increasing the slag content has a negative impact on the sulfuric acid resistance of fly ash GP binders. The visual deterioration increases as the slag content increases due to increasing calcium content resulting in the formation of C-A-S-H gel compared with N-A-S-H gel formed in the neat fly ash GPs. Gels with higher calcium content are more susceptible to decalcification and the formation of greater amounts of gypsum which causes expansion. Only small amounts of gypsum were formed in the fly ash GPs mainly inside hollow fly ash particles. On the other hand, fly ash GP mixes have a higher porosity which is reduced as the slag content increases due to the formation of space filling C-A-S-H gel. Therefore, as the slag content is increased the porosity is decreased and the alkalinity loss becomes smaller which suggest the penetration depth of acid is smaller. Nonetheless, the larger depth of acid penetration appears to have little effect on the fly ash GP materials overall as the corroded zone remained attached to the undamaged core because the reaction products have more resistance to sulfuric acid attack than those produced as the slag content increases.

- Increasing the alkaline activator dosage has very little impact on the sulfuric acid resistance of neat fly ash GP materials. The visual appearance, mass loss and compressive strength loss are all comparable after 56 days of acid attack. The reaction products are similar, hence very little difference was noted from XRD, TGA and FTIR analysis. The only difference is in terms of the alkalinity loss because the increased activator dosage results in decreased porosity which in turn reduces the alkalinity loss. Overall, the increased activator dosage offers very little increase in sulfuric acid resistance. However, if a highly acid resistant material and also a high compressive strength were required, increasing the activator dosage of fly ash GP materials may prove a suitable option.

- Compared with PC materials, fly ash and slag GPs have superior sulfuric acid resistance. The visual appearance and mass loss show favourable results for the GP mixes. The alkalinity loss and porosity values for the PC mortars are comparable to those for GP mixes with increased slag content. However, the PC samples are significantly deteriorated whereas the GP samples have remained more intact despite the acid ingress. The main disadvantage of the PC materials is the nature of their reaction products; calcium hydroxide, ettringite, AFm phases and C-S-H gel with a high $\mathrm{Ca} / \mathrm{Si}$ ratio. These are susceptible to sulfuric acid attack leaving behind a porous layer where gypsum is formed causing expansion and breakdown. A significant 
advantage for the sulfuric acid resistance of GP materials is that they do not contain calcium hydroxide and have a lower $\mathrm{Ca} / \mathrm{Si}$ ratio than $\mathrm{PC}$ materials.

The durability of concrete is an increasingly important property for concrete due to the demand for structures with a long service life and minimal maintenance costs. One of the major causes of concrete deterioration worldwide is sulfuric acid attack from acid rain, industrial processes and wastewater systems. The growing demand for more environmentally friendly construction materials has made geopolymer binders an alternative option for the cement and concrete industry. This research highlights that geopolymer binders may also provide improved durability to sulfuric acid attack which can significantly increase the service life and decrease the maintenance costs associated with concrete structures.

\section{Acknowledgements}

The authors are grateful to the School of Natural and Built Environment for provided facilities and would like to thank Dr. Mark Russell, Queen's University Belfast for his support and technical assistance. The research studentship provided by the Department for the Economy (DfE), Northern Ireland is also gratefully acknowledged.

\section{References}

[1] T. Dyer, Concrete Durability. Boca Raton, USA: CRC Press, 2014.

[2] S. Miyamoto, H. Minagawa, and M. Hisada, "Deterioration rate of hardened cement caused by high concentrated mixed acid attack," Constr. Build. Mater., vol. 67, pp. 47-54, 2014.

[3] T. Gutberlet, H. Hilbig, and R. E. Beddoe, "Acid attack on hydrated cement - Effect of mineral acids on the degradation process," Cem. Concr. Res., vol. 74, pp. 35-43, 2015.

[4] T. Dyer, "Chemical mechanisms of concrete degradation," in Concrete Durability, Boca Raton, USA: CRC Press, 2014, pp. 99-182.

[5] S. Xie, L. Qi, and D. Zhou, "Investigation of the effects of acid rain on the deterioration of cement concrete using accelerated tests established in laboratory," Atmos. Environ., vol. 38, pp. 4457-4466, 2004.

[6] B. Chatveera and P. Lertwattanaruk, "Evaluation of nitric and acetic acid resistance of cement mortars containing high-volume black rice husk ash," J. Environ. Manage., vol. 133, pp. 365373, 2014.

[7] M. O'Connell, C. McNally, and M. G. Richardson, "Biochemical attack on concrete in wastewater applications: A state of the art review," Cem. Concr. Compos., vol. 32, pp. 479$485,2010$.

[8] E. Hewayde, M. L. Nehdi, E. Allouche, and G. Nakhla, "Using concrete admixtures for sulphuric acid resistance," Proc. Inst. Civ. Eng. - Constr. Mater., vol. 160, no. CM1, pp. 25-35, 2007.

[9] N. De Belie, J. Monteny, A. Beeldens, E. Vincke, D. Van Gemert, and W. Verstraete, "Experimental research and prediction of the effect of chemical and biogenic sulfuric acid on different types of commercially produced concrete sewer pipes," Cem. Concr. Res., vol. 34, no. 12, pp. 2223-2236, Dec. 2004.

[10] M. P. Lavigne, A. Bertron, C. Botanch, L. Auer, G. Hernandez-Raquet, A. Cockx, J. N. Foussard, G. Escadeillas, and E. Paul, "Innovative approach to simulating the biodeterioration of industrial cementitious products in sewer environment. Part II: Validation on CAC and 
BFSC linings," Cem. Concr. Res., vol. 79, pp. 409-418, 2016.

[11] B. Huber, H. Hilbig, M. M. Mago, J. E. Drewes, and E. Müller, "Comparative analysis of biogenic and chemical sulfuric acid attack on hardened cement paste using laser ablation-ICPMS," Cem. Concr. Res., vol. 87, pp. 14-21, 2016.

[12] K. L. Scrivener and N. De Belie, "Bacteriogenic sulfuric acid attack of cementitious materials in sewage systems," in Performance of Cement-Based Materials in Aggressive Aqueous Environments, M. Alexander, A. Bertron, and N. De Belie, Eds. Dordrecht, Germany: Springer, 2013, pp. 305-318.

[13] M. T. Bassuoni and M. L. Nehdi, "Resistance of self-consolidating concrete to sulfuric acid attack with consecutive pH reduction," Cem. Concr. Res., vol. 37, pp. 1070-1084, 2007.

[14] T. Pyatina and T. Sugama, "Acid resistance of calcium aluminate cement - fly ash F blends," Adv. Cem. Res., vol. 28, no. 7, pp. 433-457, 2016.

[15] P. Duxson, J. L. Provis, G. C. Lukey, and J. S. J. van Deventer, "The role of inorganic polymer technology in the development of 'green concrete,"' Cem. Concr. Res., vol. 37, pp. 1590-1597, 2007.

[16] B. Sabir, S. Wild, and J. Bai, "Metakaolin and calcined clays as pozzolans for concrete: a review," Cem. Concr. Compos., vol. 23, pp. 441-454, 2001.

[17] A. M. Rashad, "Alkali-activated metakaolin: A short guide for civil engineer - an overview," Constr. Build. Mater., vol. 41, pp. 751-765, 2013.

[18] Z. Zhang, J. L. Provis, A. Reid, and H. Wang, "Geopolymer foam concrete: An emerging material for sustainable construction," Constr. Build. Mater., vol. 56, pp. 113-127, 2014.

[19] R. Vinai, A. Rafeet, M. Soutsos, and W. Sha, "The role of water content and paste proportion on physico-mechanical properties of alkali activated fly ash - ggbs concrete," J. Sustain. Metall., vol. 2, pp. 51-61, 2016.

[20] R. M. Andrew, "Global $\mathrm{CO}_{2}$ emissions from cement production," Earth Syst. Sci. Data, vol. 10, pp. 195-217, 2018.

[21] P. S. Deb, P. Nath, and P. K. Sarker, "The effects of ground granulated blast-furnace slag blending with fly ash and activator content on the workability and strength properties of geopolymer concrete cured at ambient temperature," Mater. Des., vol. 62, pp. 32-39, 2014.

[22] B. C. McLellan, R. P. Williams, J. Lay, A. van Riessen, and G. D. Corder, "Costs and carbon emissions for geopolymer pastes in comparison to ordinary portland cement," J. Clean. Prod., vol. 19, no. 9-10, pp. 1080-1090, Jun. 2011.

[23] M. Jiang, X. Chen, F. Rajabipour, and C. T. Hendrickson, "Comparative life cycle assessment of conventional, glass powder, and alkali-activated slag concrete and mortar," J. Infrastruct. Syst., vol. 20, no. 4, pp. 1-9, 2014.

[24] G. Habert, J. B. d'Espinose de Lacaillerie, and N. Roussel, "An environmental evaluation of geopolymer based concrete production: reviewing current research trends," J. Clean. Prod., vol. 19, no. 11, pp. 1229-1238, Jul. 2011.

[25] M. Kovtun, M. Ziolkowski, J. Shekhovtsova, and E. Kearsley, "Direct electric curing of alkaliactivated fly ash concretes: a tool for wider utilization of fly ashes," J. Clean. Prod., vol. 133, pp. 220-227, 2016.

[26] C. Ban Cheah, K. Yaw Chung, M. Ramli, and G. Keat Lim, "The engineering properties and microstructure development of cement mortar containing high volume of inter-grinded GGBS and PFA cured at ambient temperature," Constr. Build. Mater., vol. 122, pp. 683-693, 2016.

[27] H. Rostami and W. Brendley, "Alkali ash material: A novel fly ash-based cement," Environ. Sci. Technol., vol. 37, no. 15, pp. 3454-3457, 2003.

[28] S. Thokchom, P. Ghosh, and S. Ghosh, "Resistance of fly ash based geopolymer mortars in sulfuric acid," J. Eng. Appl. Sci., vol. 4, no. 1, pp. 65-70, 2009.

[29] S. Thokchom, P. Ghosh, and S. Ghosh, "Effect of water absorption, porosity and sorptivity on durability of geopolymer mortars," J. Eng. Appl. Sci., vol. 4, no. 7, pp. 28-32, 2009.

[30] T. Bakharev, "Resistance of geopolymer materials to acid attack," Cem. Concr. Res., vol. 35, pp. 658-670, 2005.

[31] N. K. Lee and H. K. Lee, "Influence of the slag content on the chloride and sulfuric acid resistances of alkali-activated fly ash / slag paste," Cem. Concr. Compos., vol. 72, pp. 168-179, 2016. 
[32] R. R. Lloyd, J. L. Provis, and J. S. J. van Deventer, "Acid resistance of inorganic polymer binders. 1. Corrosion rate," Mater. Struct., vol. 45, no. 1-2, pp. 1-14, 2012.

[33] A. Allahverdi and F. Škvára, "Sulfuric acid attack on hardened paste of geopolymer cements Part 1. Mechanism of corrosion at relatively high concentrations," Ceramics, vol. 49, no. 4, pp. 225-229, 2005.

[34] A. Allahverdi and F. Škvára, "Sulfuric acid attack on hardened paste of geopolymer cements Part 2. Corrosion mechanism at mild and relatively low concentrations," Ceramics, vol. 50, no. 1 , pp. 1-4, 2006.

[35] K. Abora, I. Belena, S. A. Bernal, A. Dunster, P. A. Nixon, J. L. Provis, A. Tagnit-Hamou, and F. Winnefeld, "Durability and testing - chemical matrix degradation processes," in Alkali Activated Materials, J. L. Provis and J. S. J. van Deventer, Eds. Dordrecht, Germany: Springer, 2014, pp. 177-221.

[36] V. Zivica, "Acidic attack of cement based materials - a review Part 3: research and test methods," Constr. Build. Mater., vol. 18, pp. 683-688, 2004.

[37] S. A. Bernal, E. D. Rodríguez, R. M. de Gutierrez, and J. L. Provis, "Performance of alkaliactivated slag mortars exposed to acids," J. Sustain. Cem. Mater., vol. 1, pp. 37-41, 2012.

[38] British Standards Institution, "BS EN 450-1:2012 - Fly ash for concrete. Definition, specifications and conformity criteria," London, UK, 2012.

[39] British Standards Institution, "BS EN 15167-1:2006 - Ground granulated blast furnace slag for use in concrete, mortar and grout. Definitions, specifications and conformity criteria," London, UK, 2006.

[40] British Standards Institution, "BS EN 197-1:2011 Cement Part 1: Composition, specifications and conformity criteria for common cements," London, UK, 2011.

[41] V. Zivica and A. Bajza, "Acidic attack of cement-based materials - a review Part 2. Factors of rate of acidic attack and protective measures," Constr. Build. Mater., vol. 16, no. 4, pp. 215222, 2002.

[42] British Standards Institution, "BS 812-2:1995 Testing aggregates. Methods for determination of density," London, UK, 1995.

[43] A. Rafeet, R. Vinai, W. Sha, and M. Soutsos, "Alkali activated fuel ash and slag mixes: Optimization study from mortars to concrete building blocks," in Proceedings of 34th Cement and Concrete Science Conference and Workshop on Waste Cementation, 2014, pp. 349-353.

[44] A. Rafeet, "Mix design, fresh and hardened properties and microstructural characterization of alkali-activated concrete based on PFA/GGBS blends," Queen's University Belfast, PhD thesis, 2016.

[45] A. Rafeet, R. Vinai, M. Soutsos, and W. Sha, "Guidelines for mix proportioning of fly ash/GGBS based alkali activated concretes," Constr. Build. Mater., vol. 147, pp. 130-142, 2017.

[46] J. Kwasny, M. N. Soutsos, J. A. McIntosh, and D. J. Cleland, "banahCEM - comparison of properties of a laterite-based geopolymer with conventional concrete," in Proceedings of 9th International Concrete Conference 2016: Environment, Efficiency and Economic Challenges for Concrete, 2016, pp. 383-394.

[47] J. Kwasny, M. N. Soutsos, J. A. McIntosh, and D. J. Cleland, "Comparison of the effects of mix proportion parameters on behaviour of geopolymer and Portland cement mortars," Constr. Build. Mater., no. Under review, 2018.

[48] J. Kwasny, T. A. Aiken, M. N. Soutsos, J. A. Mcintosh, and D. J. Cleland, "Sulfate and acid resistance of lithomarge-based geopolymer mortars," Constr. Build. Mater., vol. 166, pp. 537$553,2018$.

[49] American Society for Testing and Materials, "ASTM C267 - 01(2012) Standard test methods for chemcial resistance of mortars, grouts, and monolithic surfacings and polymer concretes," 2012.

[50] L. J. Parrott and D. C. Killoh, "Carbonation in a 36-year old, in-situ concrete," Cem. Concr. Res., vol. 19, pp. 649-655, 1989.

[51] C.-F. Chang and J.-W. Chen, "The experimental investigation of concrete carbonation depth," Cem. Concr. Res., vol. 36, no. 9, pp. 1760-1767, Sep. 2006.

[52] S. Chinchón-Payá, C. Andrade, and S. Chinchón, "Indicator of carbonation front in concrete as 
substitute to phenolphthalein," Cem. Concr. Res., vol. 82, pp. 87-91, Apr. 2016.

[53] E. Liu, M. Ghandehari, C. Brückner, G. Khalil, J. Worlinsky, W. Jin, A. Sidelev, and M. A. Hyland, "Mapping high pH levels in hydrated calcium silicates," Cem. Concr. Res., vol. 95, pp. 232-239, 2017.

[54] British Standards Institution, "BS ISO 15901-1:2005 Pore size distribution and porosity of solid materials by mercury porosimetry and gas absorption. Mercury porosimetry," London, UK, 2005.

[55] J. L. Provis, R. J. Myers, C. E. White, V. Rose, and J. S. J. van Deventer, "X-ray microtomography shows pore structure and tortuosity in alkali-activated binders," Cem. Concr. Res., vol. 42, no. 6, pp. 855-864, Jun. 2012.

[56] I. Ismail, S. A. Bernal, J. L. Provis, R. San Nicolas, S. Hamdan, and J. S. J. Van Deventer, "Modification of phase evolution in alkali-activated blast furnace slag by the incorporation of fly ash," Cem. Concr. Compos., vol. 45, pp. 125-135, 2014.

[57] B. Lothenbach, K. Scrivener, and R. D. Hooton, "Supplementary cementitious materials," Cem. Concr. Res., vol. 41, pp. 1244-1256, 2011.

[58] A. Noushini and A. Castel, "The effect of heat-curing on transport properties of low-calcium fly ash-based geopolymer concrete," Constr. Build. Mater., vol. 112, pp. 464-477, 2016.

[59] R. R. Lloyd, J. L. Provis, and J. S. J. Van Deventer, "Microscopy and microanalysis of inorganic polymer cements. 1: Remnant fly ash particles," J. Mater. Sci., vol. 44, pp. 608-619, 2009.

[60] S. A. Bernal, J. L. Provis, B. Walkley, R. San Nicolas, J. D. Gehman, D. G. Brice, A. R. Kilcullen, P. Duxson, and J. S. J. van Deventer, "Gel nanostructure in alkali-activated binders based on slag and fly ash, and effects of accelerated carbonation," Cem. Concr. Res., vol. 53, pp. 127-144, Nov. 2013.

[61] C. R. Shearer, J. L. Provis, S. A. Bernal, and K. E. Kurtis, "Alkali-activation potential of biomass-coal co-fired fly ash," Cem. Concr. Compos., vol. 73, pp. 62-74, Oct. 2016.

[62] S. D. Wang and K. L. Scrivener, "Hydration products of alkali activated slag cement," Cem. Concr. Res., vol. 25, no. 3, pp. 561-571, 1995.

[63] A. Fernández-Jiménez, F. Puertas, I. Sobrados, and J. Sanz, "Structure of calcium silicate hydrates formed in alkaline-activated slag: Influence of the type of alkaline activator," $\mathrm{J}$. Am. Ceram. Soc., vol. 86, no. 8, pp. 1389-1394, 2003.

[64] M. Ben Haha, G. Le Saout, F. Winnefeld, and B. Lothenbach, "Influence of activator type on hydration kinetics, hydrate assemblage and microstructural development of alkali activated blast-furnace slags," Cem. Concr. Res., vol. 41, pp. 301-310, 2011.

[65] S. A. Bernal, R. San Nicolas, R. J. Myers, R. Mejía De Gutiérrez, F. Puertas, J. S. J. Van Deventer, and J. L. Provis, "MgO content of slag controls phase evolution and structural changes induced by accelerated carbonation in alkali-activated binders," Cem. Concr. Res., vol. 57, pp. 33-43, 2014.

[66] F. Puertas, M. Palacios, H. Manzano, J. S. Dolado, A. Rico, and J. Rodríguez, "A model for the C-A-S-H gel formed in alkali-activated slag cements," J. Eur. Ceram. Soc., vol. 31, pp. 20432056, 2011.

[67] N. K. Lee, J. G. Jang, and H. K. Lee, "Shrinkage characteristics of alkali-activated fly ash/slag paste and mortar at early ages," Cem. Concr. Compos., vol. 53, pp. 239-248, Oct. 2014.

[68] T. Matschei, B. Lothenbach, and F. P. Glasser, "The AFm phase in Portland cement," Cem. Concr. Res., vol. 37, pp. 118-130, 2007.

[69] L. G. Baquerizo, T. Matschei, K. L. Scrivener, M. Saeidpour, and L. Wadsö, "Hydration states of AFm cement phases," Cem. Concr. Res., vol. 73, pp. 143-157, 2015.

[70] B. Z. Dilnesa, E. Wieland, B. Lothenbach, R. Dähn, and K. L. Scrivener, "Fe-containing phases in hydrated cements," Cem. Concr. Res., vol. 58, pp. 45-55, 2014.

[71] F. Bellmann and J. Stark, "The role of calcium hydroxide in the formation of thaumasite," Cem. Concr. Res., vol. 38, pp. 1154-1161, 2008.

[72] X. Gao, Q. L. Yu, and H. J. H. Brouwers, "Reaction kinetics, gel character and strength of ambient temperature cured alkali activated slag-fly ash blends," Constr. Build. Mater., vol. 80, pp. 105-115, Apr. 2015.

[73] L. Alarcon-Ruiz, G. Platret, E. Massieu, and A. Ehrlacher, "The use of thermal analysis in 
assessing the effect of temperature on a cement paste," Cem. Concr. Res., vol. 35, no. 3, pp. 609-613, 2005.

[74] M. Ben Haha, B. Lothenbach, G. Le Saout, and F. Winnefeld, "Influence of slag chemistry on the hydration of alkali-activated blast-furnace slag - Part II: Effect of $\mathrm{Al}_{2} \mathrm{O}_{3}$," Cem. Concr. Res., vol. 42, no. 1, pp. 74-83, Jan. 2012.

[75] A. Fernández-Jiménez, A. Palomo, J. Y. Pastor, and A. Martín, "New cementitious materials based on alkali-activated fly ash: Performance at high temperatures," J. Am. Ceram. Soc., vol. 91, no. 10, pp. 3308-3314, 2008.

[76] I. Ismail, S. A. Bernal, J. L. Provis, S. Hamdan, and J. S. J. Van Deventer, "Drying-induced changes in the structure of alkali-activated pastes," J. Mater. Sci., vol. 48, pp. 3566-3577, 2013.

[77] C. Hall, P. Barnes, A. D. Billimore, A. C. Jupe, and X. Turrillas, "Thermal decomposition of ettringite $\mathrm{Ca}_{6}\left[\mathrm{Al}(\mathrm{OH})_{6}\right]_{2}\left(\mathrm{SO}_{4}\right)_{3} \cdot 26 \mathrm{H}_{2} \mathrm{O}$," J. Chem. Soc. - Faraday Trans., vol. 92, no. 12, pp. 2125-2129, 1996.

[78] Q. Zhou and F. P. Glasser, "Thermal stability and decomposition mechanisms of ettringite at $<120^{\circ}$ C," Cem. Concr. Res., vol. 31, pp. 1333-1339, 2001.

[79] Q. Zhou, E. E. Lachowski, and F. P. Glasser, "Metaettringite, a decomposition product of ettringite," Cem. Concr. Res., vol. 34, pp. 703-710, 2004.

[80] B. Lothenbach, G. Le Saout, E. Gallucci, and K. Scrivener, "Influence of limestone on the hydration of Portland cements," Cem. Concr. Res., vol. 38, pp. 848-860, 2008.

[81] B. Z. Dilnesa, B. Lothenbach, G. Le Saout, G. Renaudin, A. Mesbah, Y. Filinchuk, A. Wichser, and E. Wieland, "Iron in carbonate containing AFm phases," Cem. Concr. Res., vol. 41, no. 3, pp. 311-323, 2011.

[82] M. Zajac, A. Rossberg, G. Le Saout, and B. Lothenbach, "Influence of limestone and anhydrite on the hydration of Portland cements," Cem. Concr. Compos., vol. 46, pp. 99-108, 2014.

[83] A. Chaipanich and T. Nochaiya, "Thermal analysis and microstructure of Portland cement-fly ash-silica fume pastes," J. Therm. Anal. Calorim., vol. 99, pp. 487-493, 2010.

[84] T. Nochaiya, W. Wongkeo, K. Pimraksa, and A. Chaipanich, "Microstructural, physical, and thermal analyses of Portland cement-fly ash-calcium hydroxide blended pastes," $J$. Therm. Anal. Calorim., vol. 100, pp. 101-108, 2010.

[85] G. C. Bye, Portland Cement, 2nd ed. London, UK: Thomas Telford Publishing, 1999.

[86] C. A. Strydom, D. L. Hudson-Lamb, J. H. Potgieter, and E. Dagg, "The thermal dehydration of synthetic gypsum," Thermochim. Acta, vol. 269-270, pp. 631-638, 1995.

[87] M. Singh and M. Garg, "Making of anhydrite cement from waste gypsum," Cem. Concr. Res., vol. 30 , no. 4 , pp. 571-577, 2000.

[88] A. Palomo, M. T. Blanco-Varela, M. L. Granizo, F. Puertas, T. Vazquez, and M. W. Grutzeck, "Chemical stability of cementitious materials based on metakaolin," Cem. Concr. Res., vol. 29, no. 7, pp. 997-1004, 1999.

[89] X. X. Gao, P. Michaud, E. Joussein, and S. Rossignol, "Behavior of metakaolin-based potassium geopolymers in acidic solutions," J. Non. Cryst. Solids, vol. 380, pp. 95-102, 2013.

[90] R. R. Hill and D. A. E. Rendell, The Interpretation of Infrared Spectra. London, UK: Heyden \& Son, 1975.

[91] B. Smith, Infrared Spectral Interpretation. Boca Raton, USA: CRC Press, 1999.

[92] F. Puertas and A. Fernández-Jiménez, "Mineralogical and microstructural characterisation of alkali-activated fly ash/slag pastes," Cem. Concr. Compos., vol. 25, pp. 287-292, 2003.

[93] A. Hajimohammadi, J. L. Provis, and J. S. J. Van Deventer, "The effect of silica availability on the mechanism of geopolymerisation," Cem. Concr. Res., vol. 41, pp. 210-216, 2011.

[94] I. García-Lodeiro, A. Fernández-Jiménez, M. T. Blanco, and A. Palomo, "FTIR study of the sol-gel synthesis of cementitious gels: C-S-H and N-A-S-H," J. Sol-Gel Sci. Technol., vol. 45, pp. 63-72, 2008.

[95] B. Walkley, R. San Nicolas, M.-A. Sani, G. J. Rees, J. V. Hanna, J. S. J. van Deventer, and J. L. Provis, "Phase evolution of C-(N)-A-S-H/N-A-S-H gel blends investigated via alkaliactivation of synthetic calcium aluminosilicate precursors," Cem. Concr. Res., vol. 89, pp. 120-135, 2016.

[96] I. García Lodeiro, D. E. Macphee, A. Palomo, and A. Fernández-Jiménez, "Effect of alkalis on 
fresh C-S-H gels. FTIR analysis," Cem. Concr. Res., vol. 39, pp. 147-153, 2009.

[97] R. B. Perkins and C. D. Palmer, "Solubility of ettringite $\left(\mathrm{Ca} 6\left[\mathrm{Al}(\mathrm{OH})_{6}\right]_{2}\left(\mathrm{SO}_{4}\right)_{3} \cdot 26 \mathrm{H}_{2} \mathrm{O}\right)$ at $5-$ 75C," Geochim. Cosmochim. Acta, vol. 63, no. 13-14, pp. 1969-1980, Jul. 1999.

[98] Z. Bascarevic, M. Komljenovic, Z. Miladinovic, V. Nikolic, N. Marjanovic, Z. Zujovic, and R. Petrovic, "Effects of the concentrated $\mathrm{NH}_{4} \mathrm{NO}_{3}$ solution on mechanical properties and structure of the fly ash based geopolymers," Constr. Build. Mater., vol. 41, no. 3, pp. 570-579, 2013.

[99] V. C. Farmer, The infrared spectra of minerals. London, UK: Bartholomew Press, 1974.

[100] J. C. Doadrio, D. Arcos, M. V. Cabanas, and M. Vallet-Regi, "Calcium sulphate-based cements containing cephalexin," Biomaterials, vol. 25, pp. 2629-2635, 2004.

[101] C. Yue, S. Li, K. Ding, and N. Zhong, "Thermodynamics and kinetics of reactions between C1-C3 hydrocarbons and calcium sulfate in deep carbonate reservoirs," Geochem. J., vol. 40, pp. 87-94, 2006.

[102] M. A. M. Ariffin, M. A. R. Bhutta, M. W. Hussin, M. Mohd Tahir, and N. Aziah, "Sulfuric acid resistance of blended ash geopolymer concrete," Constr. Build. Mater., vol. 43, pp. 80-86, 2013.

[103] S. Borhan, S. Hesaraki, and S. Ahmadzadeh-Asl, "Evaluation of colloidal silica suspension as efficient additive for improving physicochemical and in vitro biological properties of calcium sulfate-based nanocomposite bone cement," J. Mater. Sci. Mater. Med., vol. 21, pp. 3171$3181,2010$.

[104] A. Putnis and B. Winkler, "In situ IR spectroscopic and thermogravimetric study of the dehydration of gypsum," Mineral. Mag., vol. 54, pp. 123-128, 1990.

[105] L. Bragg, G. F. Claringbull, and W. H. Taylor, The Crystalline State. London, UK: G. Bell \& Sons, 1965.

[106] A. Fernández-Jiménez and A. Palomo, "Mid-infrared spectroscopic studies of alkali-activated fly ash structure," Microporous Mesoporous Mater., vol. 86, no. 1-3, pp. 207-214, 2005.

[107] M. Criado, A. Fernández-Jiménez, and A. Palomo, "Alkali activation of fly ash: Effect of the $\mathrm{SiO}_{2} / \mathrm{Na}_{2} \mathrm{O}$ ratio Part I: FTIR study," Microporous Mesoporous Mater., vol. 106, pp. 180-191, 2007.

[108] I. Garcia-Lodeiro, A. Palomo, A. Fernández-Jiménez, and D. E. Macphee, "Compatibility studies between N-A-S-H and C-A-S-H gels. Study in the ternary diagram $\mathrm{Na}_{2} \mathrm{O}-\mathrm{CaO}-\mathrm{Al}_{2} \mathrm{O}_{3}$ $\mathrm{SiO}_{2}-\mathrm{H}_{2} \mathrm{O}$," Cem. Concr. Res., vol. 41, pp. 923-931, 2011.

[109] N. K. Lee and H. K. Lee, "Reactivity and reaction products of alkali-activated, fly ash/slag paste," Constr. Build. Mater., vol. 81, pp. 303-312, 2015.

[110] M. Komljenovic, Z. Bascarevic, N. Marjanovic, and V. Nikolic, "Decalcification resistance of alkali-activated slag," J. Hazard. Mater., vol. 233, pp. 112-121, 2012.

[111] J. Aliques-Granero, T. M. Tognonvi, and A. Tagnit-Hamou, "Durability test methods and their application to AAMs: case of sulfuric-acid resistance," Mater. Struct., vol. 50, no. 36, pp. 114, 2017.

[112] J. Monteny, N. De Belie, E. Vincke, W. Verstraete, and L. Taerwe, "Chemical and microbiological tests to simulate sulfuric acid corrosion of polymer-modified concrete," Cem. Concr. Res., vol. 31, pp. 1359-1365, 2001.

[113] L. Gu, P. Visintin, and T. Bennett, "Evaluation of accelerated degradation test methods for cementitious composites subject to sulfuric acid attack; application to conventional and alkaliactivated concretes," Cem. Concr. Compos., vol. 87, pp. 187-204, Mar. 2018.

[114] F. Puertas, S. Martinez-Ramirez, S. Alonso, and T. Vazquez, "Alkali-activated fly ash/slag cement: Strength behaviour and hydration products," Cem. Concr. Res., vol. 30, no. 10, pp. $1625-1632,2000$.

[115] A. Allahverdi and F. Škvára, "Nitric acid attack on hardened paste of geopolymeric cements Part 1," Ceramics, vol. 45, no. 3, pp. 81-88, 2001.

[116] A. Allahverdi and F. Škvára, "Nitric acid attack on hardened paste of geopolymeric cements Part 2," Ceramics, vol. 45, no. 4, pp. 143-149, 2001.

[117] M. Soutsos, A. P. Boyle, R. Vinai, A. Hadjierakleous, and S. J. Barnett, "Factors influencing the compressive strength of fly ash based geopolymers," Constr. Build. Mater., vol. 110, pp. 355-368, 2016.

[118] M. Chi, "Effects of modulus ratio and dosage of alkali-activated solution on the properties and 
micro-structural characteristics of alkali-activated fly ash mortars," Constr. Build. Mater., vol. 99, pp. 128-136, 2015.

[119] R. Sersale, G. Frigione, and L. Bonavita, "Acid depositions and concrete attack: Main influences," Cem. Concr. Res., vol. 28, no. 1, pp. 19-24, 1998.

[120] A. M. Izzat, A. M. M. Al Bakrt, H. Kamarudin, A. V Sandu, G. C. M. Ruzaidi, M. T. M. Faheem, and L. M. Moga, "Sulfuric acid attack on ordinary Portland cement and geopolymer material," J. Chem., vol. 64, no. 9, pp. 1011-1014, 2013.

[121] J. Duchesne and A. Bertron, "Leaching of cementitious materials by pure water and strong acids," in Performance of Cement-Based Materials in Aggressive Aqueous Environments, M. Alexander, A. Bertron, and N. De Belie, Eds. Dordrecht, Germany: Springer, 2013, pp. 91112.

[122] C. Carde and R. François, "Effect of the leaching of calcium hydroxide from cement paste on mechanical and physical properties," Cem. Concr. Res., vol. 27, no. 4, pp. 539-550, 1997.

[123] C. Carde and R. François, "Modelling the loss of strength and porosity increase due to the leaching of cement pastes," Cem. Concr. Compos., vol. 21, no. 3, pp. 181-188, 1999.

[124] C. Shi and J. A. Stegemann, "Acid corrosion resistance of different cementing materials," Cem. Concr. Res., vol. 30, no. 5, pp. 803-808, 2000.

[125] C. Varga, M. M. Alonso, R. Mejía de Gutierrez, J. Mejía, and F. Puertas, "Decalcification of alkali-activated slag pastes. Effect of the chemical composition of the slag," Mater. Struct., vol. 48, no. 3, pp. 541-555, 2014.

[126] T. A. Aiken, W. Sha, J. Kwasny, and M. N. Soutsos, "Resistance of geopolymer and Portland cement based systems to silage effluent attack," Cem. Concr. Res., vol. 92, pp. 56-65, 2017.

[127] E. K. Attiogbe and S. H. Rizkalla, "Response of concrete to sulfuric acid attack," ACI Mater. $J .$, no. November-December, pp. 481-488, 1988. 